\title{
A STUDY OF INTERGROUP CONTACT THEORY: USING STORYTELLING TO INCREASE AWARENESS OF LESBIAN AND GAY OLDER ADULTS IN LONG-TERM CARE SETTINGS
}

\author{
A Dissertation \\ presented to the Faculty of the Graduate School \\ at the University of Missouri-Columbia \\ In Partial Fulfillment \\ of the Requirements for the Degree \\ Doctor of Philosophy \\ by \\ MICHAEL D. PELTS \\ Dr. Colleen Galambos, Dissertation Supervisor \\ DECEMBER 2015
}


(C) Copyright by Michael D. Pelts 2015

All Rights Reserved 
The undersigned, appointed by the dean of the Graduate School, have examined the dissertation entitled

\section{A STUDY OF INTERGROUP CONTACT THEORY: USING STORYTELLING TO INCREASE AWARENESS OF LESBIAN AND GAY OLDER ADULTS IN LONG- TERM CARE SETTINGS}

presented by Michael D. Pelts,

a candidate for the degree of doctor of philosophy,

and hereby certify that, in their opinion, it is worthy of acceptance.

Professor Colleen Galambos

Professor Marilyn Rantz

Professor Ninive Sanchez

Professor Mansoo Yu 


\section{Dedication Page}

I dedicate this dissertation to the memory of my mother, Mary A. Pelts. The strongest person I know, my mother encouraged and supported me throughout my education. She is missed dearly. I will strive to honor her by applying the work ethic, attention to detail, high expectations, and unselfish kindness that she demonstrated every day in my research and teaching. 


\section{Acknowledgement Page}

First, thank you to my advisor and dissertation chair, Dr. Colleen Galambos. Dr. Galambos challenged me at opportune points and encouraged me when I was struggling. During the process of obtaining a Ph.D., the potential to build skills is tremendous. Dr. Galambos provided the right amount of support at the right times to help me build my research and statistical analysis skills while allowing me to develop a dissertation that is reflective of my interests and the convictions that inspired me to pursue a Ph.D.

Thank you to other committee members. To Dr. Marilyn Rantz, I express my thanks for your support in helping me secure funding and developing sites to collect data. It is an honor to have you as a mentor. Working with Dr. Rantz and Dr. Galambos on the "R01" grant was a wonderful learning opportunity that allowed me to develop my knowledge of research in many ways that I will use throughout my career in academia. I am grateful for Dr. Mansoo Yu's support and encouragement. Dr. Yu encouraged me not only with my research but also with developing my teaching skills. Dr. Ninive Sanchez, thank you for joining my committee and sharing insight. Thank you to Dr. David Albright for your input in the dissertation proposal, your support of my work, and for encouraging me to write during my doctoral studies.

I am grateful for the funding provided by the University of Missouri, Interdisciplinary Center for Aging through the Research Enrichment And Dissemination (READ) program. Funding from the READ program helped to make this research possible.

I gratefully acknowledge the University of Missouri, Sinclair School of Nursing, Quality Improvement Program (QIPMO) team. Particular thanks to Sharon Thomas, Clinical Consultant and Educator with the QIPMO team, for her assistance with securing 
sites for data collection. Thank you to the staff at The Bluffs of Columbia, Missouri; the Center for Living in Marshal, Missouri; and Ashley Manor in Boonville, Missouri who participated in this study. Thank you to Mikala Compton, student in the University of Missouri, School of Journalism for assisting with video editing. I am grateful to Laura King Danforth, fellow doctoral student, who helped with the data collection process. It was a delight to work with Laura and a great help to have a fellow student to process the observations made during data collection.

To my fellow doctoral students and other doctoral faculty, I express my thanks. This experience has stretched my thinking and changed my view of the world. It was a joy to learn with and from fellow students and faculty on this challenging journey.

Finally, I express my gratitude to Donna and Orval. Each of you so graciously shared your personal life stories. Learning about your beautiful and challenging experiences as a lesbian and gay man and your modest expressions of strength and perseverance was an honor for me. This work could not have been completed without you. Your rich stories were the foundation of this research and became the intervention for this study. Your stories will help to ease the path for generations of lesbians and gay men that follow you. Thank you. 


\section{TABLE OF CONTENTS}

ACKNOWLEDGEMENTS ................................................. ii

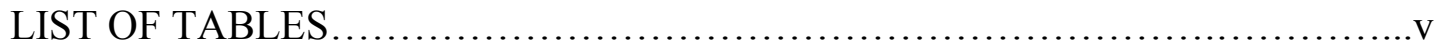

LIST OF FIGURES.................................................. vi

CHAPTER ONE: INTRODUCTION AND BACKGROUND ......................

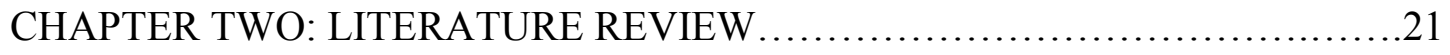

CHAPTER THREE: RESEARCH DESIGN AND METHODS......................38

CHAPTER FOUR: RESULTS......................................... 52

CHAPTER FIVE: DISCUSSION ...................................... 76

REFERENCES ..................................................... 87

APPENDIX

A. Recruitment Flyer............................................... 100

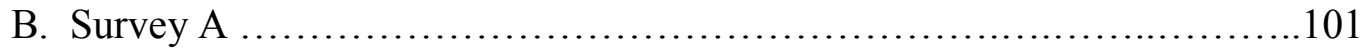

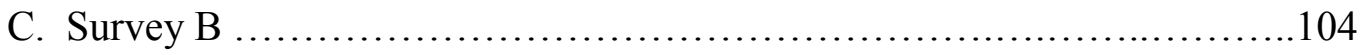

D. Role of Note-taker and Observer ................................... 107

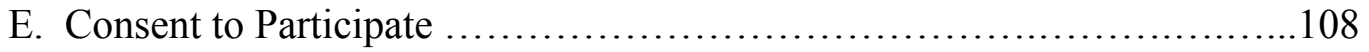

F. Group Discussion Guide ...................................... 110

G. Guide for Developing Storytelling Script ............................112

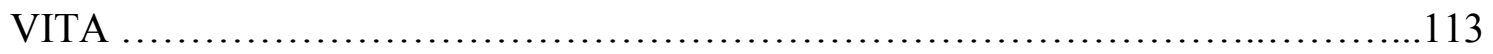




\section{LIST OF TABLES}

Table

Page

1. Operationalization and Measurement of Variables.............................43

2. Demographic and Background Characteristics of Participants ..................53

3. Descriptive Statistics for Attitudes Toward Lesbians and Gay Men ................55

4. Results of t-test and Descriptive Statistics for Attitudes Toward LG - all

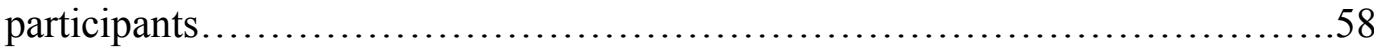

5. Results of t-test and Descriptive Statistics for Attitudes Toward LG Heterosexual Participants ..................................................59

6. Results of Round 2 Coding and Thematic Analysis............................64

7. Results of t-test and Descriptive Statistics for Difference in Pre and Post Test Attitude Scores ............................................................... 71

8. Bivariate Correlations ................................................... 72

9. Summary of Regression Analysis for Religiosity Predicting Attitudes Toward LG when Controlling for Age and Previous Acquaintance 


\section{LIST OF FIGURES}

Figure

Page

Figure 1. Visual Depiction of how IGC Works ...........................................................12

Figure 2. Embedded QUAN (qual) design .........................................

Figure 3. Wordle Depiction of the 90 Codes that Emerged During Round One...........61 


\section{CHAPTER ONE: INTRODUCTION AND BACKGROUND}

\section{Overview}

What would you do if you were old, disabled or ill - and the person feeding you put down the spoon and said that you are going to hell unless you change your sexual preference? Sound absurd? Social workers around the world say it's happening every day (Maddux, 2010).

A long-term care (LTC) setting should provide a place of comfort and safety for all residents. Adjusting to living in LTC can be difficult for any older adult (Perrin \& Powowy, 2008). Due to systematic discrimination in society, adjusting to a LTC setting for lesbian and gay (LG) older adults can be even more difficult.

The growing number of older adults suggests more people will be seeking LTC. As the population of older adults increases it is also becoming more diverse. Developing awareness of the care needs of diverse older adults is crucial to providing adequate consumer-centered LTC. Population estimates indicate that the number of people above the age of 65 is growing rapidly and will continue to grow during the next four decades. In 2010, thirteen percent of U.S. residents were over the age of 65 ; by 2030 that number is projected to be more than twenty percent (Ortman, Velkoff, \& Hogan, 2014). In 2012 there were an estimated 43 million people over the age of 65 in the United States. By 2050 , the number of people over the age of 65 is expected to double to 84 million.

Among this growing number of people who will have increased care needs as they age are a large number who identify as lesbian and gay (LG). Also referred to as sexual minorities, LG people are identified as one of the diverse groups of older adults that will require LTC at rates higher than the general population (MetLife, 2010). 
In the first chapter of this dissertation, the problem is formulated and the issues relevant to the problem are discussed. The importance of this matter to social work, the conceptual framework, statement of purpose and definition of terms are then presented. In Chapter Two, a review of the literature related to the concepts introduced in Chapter One is presented. Chapter Three provides a description of the research design, data collection methods and the analysis used to answer the research questions. In Chapter Four, the results of data analysis are presented for each research question. Finally, in Chapter Five a discussion of the findings is presented and implications for social work research and practice are discussed.

\section{Formulation of the Problem}

Two primary factors suggest that older LG adults are likely to need LTC services at rates higher than the general population. First, older LG adults are less likely to have spouses, partners or children - first line caregivers (MetLife, 2010). Secondly, older LG adults have an increased need for care and specialized care needs when compared to the general population (Fredriksen-Goldsen, 2011). Though LG older adults are more likely to need LTC services they are also more likely to prolong or avoid seeking LTC services in fear of discrimination and stigmatization (MetLife, 2010). The tendency to avoid seeking care, stems from marginalization of sexual minorities in society that extends to LTC staff. Studies show that the stigmatization and discrimination of LG older adults in LTC facilities is related to a lack of awareness and training for LTC staff (Bell, BernKlug, Kramer, \& Saunders, 2010; Morales, King, Hiler, Coopwood, \& Wayland, 2014). Yet, few studies have explored training approaches that increase awareness of sexual minorities with LTC staff. Without training related to serving sexual minorities, LTC 
care staff that hold negative attitudes towards LG people are likely to maintain such attitudes that may impact the quality of care (Morales et al., 2014).

\section{Discussion of Issues}

\section{Aging of LG Population}

Obtaining accurate data on LG older adults can be difficult because the U.S. Census Bureau does not measure sexual orientation (Fredriksen-Goldsen \& Kim, 2014). A report by the Lesbian, Gay, Bisexual and Transgender (LGBT) Movement Advancement Project and the Services \& Advocacy for Gay, Lesbian, Bisexual \& Transgender Elders estimates there are currently 1.5 million Americans over the age of 65 that identify as LG (Hudson, 2011). The same report estimates the number of LG people over the age of 65 will double to 3 million by the year 2030 as a result of the baby boom generation. Society's depiction of sexual minorities has a strong influence on how older LG adults view situations. Reviewing the historical experiences can aid in understanding how sexual minorities perceive their surroundings.

Historical context. Today's LG older adults lived during a time when they were highly marginalized and stigmatized by society (Morales et al., 2014). Many were in late adolescence, a time when sexual orientation becomes salient, when they witnessed the medical pathology of homosexuality. In 1952 homosexuality was added to the Diagnostic and Statistical Manual (DSM) as a sociopathic personality disorder. Even though the sociopath label was removed in 1973, homosexuality remained as a diagnosis in different forms in the DSM until 1986 (Pickett, 2009).

Older LG adults today lived during pivotal points of the gay civil rights movement. The Stonewall riots that took place in 1969 are considered the beginning of 
the modern gay civil rights movement (Pickett, 2009). The Stonewall Inn, a bar in New York City, was raided by police on June 27, 1969, a time when people were arrested for same sex behaviors. Although gay men and lesbians often went peacefully during raids that were common at the time, on this occasion patrons of the bar rebelled. The Stonewall riots were broadcast around the nation and the world including efforts by the media to portray sexual minorities as deviant or criminal (Fejes \& Petrich, 1993). The riots also brought the gay rights movement from underground to the public eye in other ways.

Older LG adults were young adults when the first openly LG public officials were elected to office. First Kathy Kozachenko on the Ann Arbor, Michigan city council in 1974 and then Elaine Noble to the Massachusetts State house in 1975 (Retter, 1998). Likely the most well-known and first openly gay man elected to public office was Harvey Milk, who campaigned for laws that protected sexual minorities against discrimination. Older adults witnessed the election of Milk to the San Francisco Board of Supervisors in 1977 and his assassination only 11 months later (Pickett, 2009).

A new disease appeared in 1981 that disproportionally impacted gay men and slowed the gay civil rights movement. Older LG adults witnessed the stigmatization associated with HIV and AIDS, diseases that were labeled the gay cancer, and the gay plague. They also witnessed a lack of an official federal government response and civil neglect that contributed to the spread of HIV and AIDS and the deaths of thousands of their peers (Shilts, 1994; Valdiserri, 2011).

LG older adults living today witnessed a resurgence of the gay civil rights movement. Sexual minorities have gained access to some social institutions and as 2014, 
live during a time when geography has a great influence on civil protections. For example, the federal government now recognizes same sex marriage, yet same sex marriage is still denied in most states (Pelts, 2014). Many other civil protections such as rights in employment and housing are only extended to sexual minorities in local jurisdictions or on a state by state basis. The effects of marginalization that stem from discrimination and stigmatization over a lifetime can impact the health of LG older adults.

Health disparities. The negative impacts on health as a result of identifying as sexual minority have been well established in the scholarly literature. Studies related to minority stress have shown that LG older adults experience disparities in health not because of identification as a sexual minority but as a result of societal stigma and discrimination (Meyer, 2003; Meyer, Dietrich, \& Schwartz, 2008; Oswalt \& Wyatt, 2011). Older LG adults are at risk of double jeopardy as a result of age and identification as a sexual minority.

The U.S. Department of Health and Human Services Healthy People 2020 report (2011) identifies both older adults and sexual minorities as two of six groups affected by health disparities. In a comprehensive report about sexual minorities, the Institute of Medicine (IOM), Committee on Lesbian Gay Bisexual and Transgender Health Issues (2011) found that older sexual minorities are more likely to rate their health as poor when compared to others. For example, older lesbians had greater risk of reproductive cancers, higher rates of obesity and higher risk for cardiovascular disease than heterosexual women. Gay and bisexual men had higher rates of HIV/AIDS and 29\% of people living with AIDS/HIV are over the age of 50. For both lesbian and gay older adults, the 
psychological distress of chronic discrimination results in higher levels of physical and mental disability.

Compounding their increased needs is the lack of first line support and care giving. LG baby boomers are twice as likely to not have children, spouses or partners, who are the largest providers of care for older adults (IOM, 2011). Living in isolation in high numbers and fear of discrimination in LTC facilities leaves LG older adults at high risk for abuse, neglect and exploitation (Hudson, 2011). Prejudice that manifests in the form of negative attitudes towards sexual minorities can perpetuate the situation.

\section{Prejudice}

Even though prejudice toward people based on sexual orientation is similar to other forms of prejudice there are also differences (Herek \& McLemore, 2013). Primarily, prejudice directed towards sexual minorities is still allowed with little or no protections in many social structures and large parts of society. For example, the federal government requires hospitals that participate in Medicaid or Medicare programs to provide equal access, yet only 26 states have policies that require equal access to same sex partners in hospitals (Human Rights Campaign [HRC], 2014a). Only 21 states prohibit discrimination based on sexual orientation regarding access to public entities such as government facilities and general businesses (HRC, 2014b). Likewise, only 21 states prohibit discrimination based on sexual orientation in housing laws (HRC, 2014c). The absence of laws and policies that provide institutional support combined with a lack of awareness can perpetuate stigmatization that leads to discriminatory practices (Allport, 1954). 
Because stigma towards sexual minorities is prevalent in society, many people internalize negative attitudes to some extent through everyday socialization (Herek \& McLemore, 2013). The negative attitudes created by stigmatization are oftentimes supported by group norms. The need to continually affirm group norms results in negative behavior responses that become automatic when LG people are present or the topic of sexual minorities arises. These automatic responses may manifest in service delivery. Prejudice in the caregiving setting that manifests as negative attitudes influences whether or not sexual minorities seek LTC services.

\section{Reluctance to Seek LTC}

Even though older LG adults are likely to experience greater healthcare needs in old age, they are less likely to access LTC services. In addition to experiencing greater healthcare needs, older sexual minorities are also more likely to live alone, increasing their risks of unmet healthcare needs. In a study with 210 sexual minorities, $63 \%$ reported living alone (Brennan-Ing, Seidel, Larson, \& Karpiak, 2013). That number was significantly higher for gay men (71\%) than lesbian women (39\%). The lived experiences of stigma and discrimination that stem from prejudice effect how older adults perceive their surroundings - including how they view and are viewed in LTC settings (MetLife, 2010). The likelihood that an older LG adult was victimized due to sexual orientation is high. Reports show that on average, sexual minorities experienced four incidences of victimization as a result of their sexual orientation. Sixty-five percent of older sexual minorities' experienced verbal abuse and $40 \%$ experienced physical violence (Fredriksen-Goldsen, 2011; IOM, 2011). Their lived histories, societal stigma and 
personal reactions to victimization influence how older LG adults are perceived and how they perceive LTC (IOM, 2011).

Results of the MetLife (2010) study revealed that more than half of sexual minorities believe they will receive poor care in LTC settings. Studies also show that both actual acts of discrimination from LTC providers and fears of discrimination in LTC result in older sexual minorities delaying care or avoiding care altogether (Brotman, Ryan, \& Cormier, 2003; Orel, 2006). Findings from a national study revealed that $29 \%$ of sexual minorities avoided or delayed medical care compared to $17 \%$ of heterosexuals (Hudson, 2011). The relevance of this matter to the social work profession is expanded upon next.

\section{Importance to Social Work}

Social work is the largest provider of social services in the United States and the social science committed to serving people who are the most vulnerable (National Association of Social Workers [NASW], 2008). Social workers serve older adults who live alone in their own homes; who live with partners, spouses or other family members (biological or of choice); who live in congregate housing such as assisted living facilities or independent living centers; and those who reside in skilled-nursing facilities such as nursing homes and rehabilitation facilities. Social workers are also primarily responsible for providing protective services to vulnerable populations including older adults. There is a need for information about working with older LG adults.

Fredriksen-Goldsen and Muraco (2010) found that research about sexual minority older adults is glaringly absent from the scholarly literature in the social sciences. Literature was missing in all areas including a lack of information about training to 
increase awareness and competence among LTC providers related to sexual minority older adults. Often referred to as invisible in society, victimization and a lack of inclusive care environments leave older LG adults underserved and vulnerable (Fredriksen-Goldsen \& Muraco, 2010; Morales et al., 2014).

It is expected that social workers will deliver services to all older adults in a competent and informed manner that is inclusive of sexual minorities (NASW, 2008). With additional training techniques that promote awareness, social workers can better address issues related to serving LG older adults. Finally, as the profession dedicated to serving the most marginalized and oppressed at the core of the mission (NASW, 2008), social work is well positioned to research and inform training related to increasing awareness and meeting the needs of LG older adults. In a call to action, Paluck (2006) challenged social workers scholars to generate action research based in theory to reduce prejudice and promote social inclusion of stigmatized groups.

\section{Conceptual Framework}

This study is guided by the conceptual framework of intergroup contact theory. The study also includes storytelling as the method for delivering the intervention. Finally, the study includes an embedded qualitative element informed by grounded theory. Each of these concepts are reviewed in more detail.

\section{Intergroup Contact Theory}

More than six decades ago Allport (1954) reported on the value of intergroup contact (IGC) with reducing prejudice, countering negative attitudes and increasing awareness of marginalized groups. Scholars studied and reported the impacts of contact between marginalized groups as early as the 1930's (Dovidio, Gaertner, \& Kawakami, 
2003). However, Allport framed the contact hypothesis or intergroup contact theory in his seminal work, The Nature of Prejudice in 1954. Allport's work has received tremendous attention from scholars across multiple disciplines and around the world. Prejudice is important to this study because in service delivery, the negative attitudes that accompany prejudice may manifest in the form of discrimination and stigmatization of groups of people including sexual minorities (Allport, 1954).

Allport (1954) believed that most often prejudice was not based on actual experiences. Prejudice was the result of group stereotypes that manifested over time as cognitive distortions. Groups begin to form at a young age. As a child, the family is the most influential group followed by the community and then perhaps the city and the country. Children learn loyalty to their group and as they age elements with their environment continuously reinforce their sense of belonging through social beliefs and attitudes. Homogeneity in the environment may increase prejudice and negative beliefs and attitudes towards outside members are passed from generation to generation. As a result, the targets of negative attitudes, i.e., groups of people, may be placed in a disadvantaged position for no sound reason. This behavior becomes especially problematic when there are differences in power such as caregiver and recipient of care.

Prejudice manifests in differing degrees including verbal rejection, discriminating against an entire group in activities related to equal access or service, and at the extreme, acts of physical violence and attempts to exterminate populations (Allport, 1954). In the social work profession, it is well established that a lack of contact or the lack of awareness of groups at risk for marginalization may lead to prejudice that can have negative effects on individuals and entire social groups (Dessel, Rogge, \& Garlington, 
2006; Paluck, 2006). Individuals such as older adults may be at increased risk due to age and identification with other minority groups (e.g., race, religion or sexual orientation). Increased awareness can counter the negative effects of prejudice (Allport, 1954). In order to understand how IGC can effectively reduce prejudice, it is helpful to be familiar with the terminology.

Theoretical definition of terms. The following terms are used in this study as related to IGC theory.

Attitude: Enduring beliefs that influences a person's thinking, feeling and behaviors. Individual's attitudes are highly influenced by in-groups - first parents, then family members, social groups, and larger societal influences (Allport, 1954; Ritzer, 2007)

In-group: Identification with others with the same attitudes, beliefs and behaviors that results in a sense of cohesion (Ritzer, 2007). In-group status may be fought for but most in-group identities are conferred automatically by birth or association (e.g.; family, race, sex; Allport, 1954). Maintaining in-group status requires continual effort to generate, affirm and maintain group boundaries that is achieved by emphasizing the differences of out-group members (Ritzer, 2007).

Intergroup contact: The coming together of members from different groups in structured or unstructured settings (Allport, 1954).

Out-group: A social unit of people identified by a distinguishable factor that an individual does not belong to and does not identify with (Ritzer, 2007). In research studies that look at IGC, the out-group is sometimes referred to as the target group. 
Prejudice: Attitude or beliefs towards others that are generalized to the entire group based on discernible features without warrant (Allport, 1954).

How intergroup contact works. When individuals are prejudiced towards outgroups they are likely to avoid contact with out-group members (Allport, 1954).

Structured or unstructured positive contact between in-group and out-group members can reduce prejudice and increase favorable future contact. IGC is posited to work by influencing individuals on three different levels: cognition, affect and behavior (Pettigrew, 1998). A visual depiction of How IGC Works is provided in Figure 1.
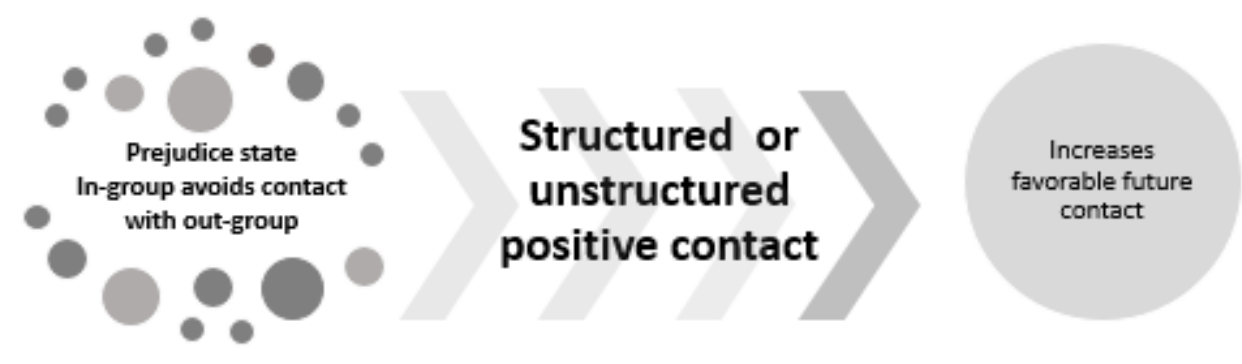

\section{Cognition \\ 2. Affect \\ 3. Behavior}

Figure 1. Visual depiction of how IGC works. Allport (1954), posited that when people are prejudiced towards out-groups they are likely to avoid contact. Structured or unstructured contact between in-group and outgroup members may reduce prejudice and increase contact by influencing people on three levels.

A step process can be used to explain how IGC contact can influence in-group members thinking about the out-group, feelings about the out-group and behaviors toward the out-group. 
Pettigrew (1998) describes four steps that make up the process of change that results from IGC. Initial IGC leads to learning about the out-group. New learning changes the negative views that in-group members hold towards out-group members. Learning about out-group members' experiences results in changing behaviors among ingroup members that leads to contact with members of the out-group. Interaction with out-group members generates affective ties associated with anxiety and empathy. Positive IGC experiences reduce anxiety related to interacting with out-group members and increases empathy of towards out-group members. Increased empathy and decreased anxiety leads to in-group reappraisal. During in-group reappraisal, members reassess their in-group norms and customs that shape how they view and interact with out-group members.

Factors such as the frequency of contact, degree of identification with the ingroup and degree of prejudice towards the out-group influence how the effects of IGC are generalized (Pettigrew, 1998). Positive IGC contact experiences can lead to generalization across situations, meaning in-group members view out-groups more positively in a variety of settings and under different circumstances. Positive IGC can also "generalize from the out-group individual to the out-group" and over time can lead to a higher form of generalization described as "generalization from the immediate outgroup to other out-groups" (Pettigrew, 1998, p. 74). In structured contact encounters, IGC can be most effective when sharing personal life experiences through methods such as storytelling. 


\section{Storytelling}

In this study storytelling is used as the intervention (the intervention is discussed in detail in Chapter Three of this dissertation). Storytelling can take many forms and is described as an interactive and universal experience common to every social group to share, connect, entertain and stimulate thinking (Alterio, 2003; Carter-Black, 2007). Throughout history, storytelling has been used to communicate culture, educate, interpret experiences and share history. Storytelling is part of the human experience that can help individuals cross cultures, make sense of the world, conduct self-reviews and can aid in the construction of new knowledge (Alterio, 2003). In his work related to IGC, Allport (1954) identified mechanisms such as storytelling as a means to reduce prejudice.

Social work and other social science scholars have challenged researchers to test the use of storytelling to increase the awareness of marginalized populations. Social work researcher Carter-Black (2007) reports on the history of storytelling in the African American community and challenged social work educators to include storytelling as part of the social work education experience. Carter-Black describes story telling as a mechanism to communicate how "we are simultaneously the same and different" (p. 41). Storytelling integrates feelings and thought (Alterio, 2003). Scholars have identified several strengths of storytelling related to training and education including the ability of stories to cross cultures, help people make sense of the world, encouraging self-review and aids in the development of new knowledge (Alterio, 2003; Davidhizar \& Lonser, 2003).

A favorable technique in the nursing profession, storytelling is reported as a training tool in nursing education programs, nursing training and nursing practice 
(Davidhizar \& Lonser, 2003; Payne, Jebb, Brathwaite, \& Crumbie, 2014). Davidhizar and Lonser (2003) reported that storytelling is underused in nursing education, training and practice. They argue that in healthcare delivery, storytelling can help nurses to consider the lived experiences of patients of differing cultures. Storytelling is posited as a means to help nursing staff develop skills to work with patients in a non-judgmental manner. Social work scholars have identified storytelling as a valuable approach to educating about the needs of sexual minorities.

In the limited social work literature that addresses storytelling and sexual minorities, including sexual minority people as part of training is identified as an approach for increasing awareness and dispelling myths (Leyva, Breshears, \& Ringstad, 2013; Rogers, Rebbe, Gardella, Worlein, \& Chamberlin, 2013). Results of these studies suggest that there is potential of storytelling to increase awareness, empathy and understanding, and storytelling may aid in making sexual minority older adults more visible.

\section{Grounded Theory}

The IOM report (2011) identifies the need for using multiple approaches to better understand issues related to attitudes towards sexual minorities. In this study, a qualitative element, guided by grounded theory, is embedded to further understand providers' attitudes and explain quantitative findings. Glaser and Strauss (1967) posit that the grounded approach can be used as an inductive method to conduct research that results in the systematic development and understanding of concepts identified by study participants. Guided by a grounded theory approach, researchers can learn directly from participants to better understand an issue (Richards \& Morse, 2013). 


\section{Statement of Purpose}

Herek and McLemore (2013) posited that the stigmatizing automatic responses that result from negative attitudes towards sexual minorities are not likely to change until those attitudes are constructively confronted. IGC is one of the most constructive means to counter negative attitudes. Contact with minorities as explained by IGC theory (Allport, 1954) has proven to be effective in reducing prejudice and improving attitudes towards many marginalized groups including sexual minorities (Pettigrew \& Tropp, 2011). When contact promotes understanding personal human experiences, the results may be stronger (Allport, 1954). The life experiences, or stories, that all older adults carry contain the element of the personal human experience. Incorporating the personal stories of older LG adults into training for LTC staff may be an effective approach to increasing awareness and decreasing negative attitudes towards older LG.

A limited number of studies show that the awareness of LG older adults is lacking among LTC staff members, and only a few studies have looked at methods to increase awareness and address negative attitudes. The IOM (2011) report identified a need to further understand the inequities in healthcare related to service delivery with LG older adults and intervention research designed to address inequities in healthcare with LG older adults as priorities for research. The report states:

Provider attitudes and education, and ways in which the care environment could be improved would provide a solid base from which to address these inequities (IOM, 2011, p. 297).

The purpose of this study is to explore the influence of IGC through the use of storytelling as a training mechanism to increase staff awareness and reduce negative 
attitudes related to serving LG older adults in LTC. This study contributes to the developing knowledge about staff training related to serving older LG adults in LTC. This study answers the following research questions:

1. How does storytelling influence LTC staff members' attitudes towards LG older adults?

a) Qualitative question: How do qualitative findings (open-ended questions and narrative from group dialogue following storytelling event) compare to quantitative findings related to attitudes of LTC staff (informs IGC theory)?

b) Qualitative question: What are the emerging themes in the narrative (informed by grounded theory)?

2. How does storytelling influence male and female respondent's attitudes towards LG differently?

3. What is the relationship between religiosity and attitudes towards LG older adults among participants?

\section{Directionality}

To explore the influence of IGC on attitudes towards LG persons, IGC theory posits that contact will impact attitudes towards LG people. Based on the assumptions of IGC, the research hypotheses are:

$\mathrm{H}_{\mathrm{a}} 1$ : Following the storytelling event, respondents will report significantly more favorable attitudes towards LG older adults;

$\mathrm{H}_{\mathrm{a}} 2$ : Following the storytelling event, female respondents will report significantly more favorable attitudes towards LG older adults than male respondents; and 
$\mathrm{H}_{\mathrm{a}} 3$ : When controlling for previous acquaintance with an LG person and age, increases in religiosity are associated with more negative attitudes towards LG older adults.

\section{Definition of Terms}

For the purpose of this study, the following definitions are used.

Bisexual: A term used to describe a person who is physically and emotionally attracted to both people of the same sex and people of opposite sex.

Family of Choice: Term used to describe those people who are social and care support that are not biologically related such as partners, close friends and other loved ones.

Gay: A term used to describe a person who is physically and emotionally attracted to a person of the same sex. Most commonly used to describe men.

Heterosexism: A belief that heterosexuality is the norm, healthier and the superior choice. Heterosexual: Term used to describe people who are primarily physically and emotionally attracted to people of the opposite sex.

Homophobia (or transphobia or biphobia): Irrational fear of lesbians, gay men, bisexual, or transgender people. Stronger than heterosexism, it suggests hatred and prejudice.

Homosexual: Clinical term used to describe a gay or lesbian person. Due to the negative connotation, it is rarely used outside of clinical or scholarly literature.

Lesbian: A term used to describe a woman who is physically and emotionally attracted to other women.

Long term care facility: For the purpose of this study, long term care is defined as a facility that provides care or support in some manner such as a nursing home, skilled nursing facility, assisted living, or independent living center.

Older adults: For this study older-adults is in reference to people over the age of 60. 
Sexual Minorities: Individuals of a sexual orientation that differs from the majority.

Sexual orientation: The term used to describe a person's physical and emotional attraction to others including lesbian, gay, bisexual or heterosexual.

Sexual Prejudice: Attitudes toward sexual minorities that manifests as a result of cultural and societal stigmatization.

\section{Assumptions}

Within this study there are several assumptions. It is assumed that some LTC care staff that participate in this study do not hold LG people in high regard. It is assumed that study participants answered survey questions honestly and openly participated in the group discussion that followed the intervention. To protect participant privacy and increase the likelihood of obtaining authentic input, all input was collected in a manner that did not use names or other personal identifying information. Finally, it is assumed that the embedded qualitative approach complements quantitative findings. Mixed methods approaches such as the embedded design utilized in this study can provide the best evidence to understand the results of an intervention (Creswell \& Clark, 2011; Greene \& Caracelli, 2003).

\section{Limitations and Delimitations}

This study is limited by the small sample size. The study is also limited as a result of geography. All data was collected in one state in the Midwest region of the United States limiting the generalizability. Finally, this study is limited by the points of measure. Even though pre and post measures were collected, outcomes were not measured after an extended period of time such as six months or one year. 
Oftentimes LG and issues related to people who identify as bisexual and transgender people are understandably combined for the purposes of advocacy and research. The intent of this study was not to exclude groups in any manner. This study acknowledges that sexual orientation and gender identity are distinctly separate and this study has a focus on sexual orientation and specifically LG populations. Bisexual older adults, transgender older adults and other groups on the spectrum of sexual and gender orientation that experience stigmatization are areas in need of additional research (Fredriksen-Goldsen et al., 2014). The distinctive environmental experiences of these groups merits separate research when looking at definitive topics (Knochel, Quam, \& Croghan, 2011).

\section{Conclusion}

This chapter provided an overview of the study. In particular, Chapter One provided a description of how stigmatization and discrimination impacts older LG adults and how negative attitudes towards LG people can impact the quality of service in LTC settings. The life experiences, or stories, that all older adults carry hold great value. Chapter Two serves as a review of the literature related to the variables in this study in detail. 


\section{CHAPTER TWO: LITERATURE REVIEW}

As presented in Chapter One, this study aims to explore the impact of storytelling as a tool to increase staff awareness and improve attitudes related to serving LG older adults. This chapter will first report on the development of IGC theory, the use of IGC in research and then specifically the use of IGC with sexual minorities as the target group. The review will then look at the literature related to factors that are important to consider when researching training related to understanding sexual minorities and the variables included in this study - previous contact, religion and gender. Healthcare providers' beliefs, attitudes and perceptions of older sexual minorities is then reviewed followed by a review of instruments used to assess attitudes.

To ensure applicable literature was identified, a systematic approach was employed. For each relevant topic area, a search was conducted using the Academic Search Complete database available via the University of Missouri libraries. The database was selected because it includes content across multiple relevant disciplines and is a comprehensive source that includes content from 7,850 peer reviewed journals (EBSCO, 2014). Electronic copies of relevant articles were secured. When copies were not available via the University of Missouri Libraries website, copies were requested and obtained via the inter-library loan process. Other search engines including SCOPUS and Google Scholar were also used intermittently to further search for specific articles or to obtain access to specific articles. Finally, references from secured articles were reviewed to identify relevant literature.

The film-making analogy suggested by Rudestam and Newton (1992) to manage literature was utilized. Articles were coded as long-shots, medium-shots or close-up. 
Long shots were treated as background material and relevant topically. Articles coded as medium-shots were looked at more closely and articles coded as close-ups were reviewed in detail.

\section{Intergroup Contact Theory}

Even before Allport (1954) coined the phrase intergroup contact theory, others were studying the effects of contact related to increasing awareness, improving relations and reducing prejudice between groups. The suggestion that contact could be used to reduce prejudice, increase awareness and improve attitudes between groups was recorded in the literature more than 20 years prior. Much of the work originally focused on relations between children of different races in school settings (Dovidio et al., 2003). Horowitz (1936) developed measures to look at the effects of contact on intergroup relations among school-aged children of different races. In another study, the intergroup relationships were studied among children from 39 racial and ethnic backgrounds (Dovidio et al., 2003; Zeligs \& Hendrickson, 1933). Contact, as measured by acquaintanceship, was shown to have the most significant positive effects on racial attitudes towards peers of other races.

The work related to exploring the effects of contact was extended to other age groups. Initially, it was used to study interactions between white college students and black community leaders (Smith, 1943). When comparing white students who participated in contact situations with students in the control group, contact resulted in statistically significant improvements in attitudes toward black community leaders. Results were substantiated at 30 day follow-up. The battlefields of World War II were said to have offered a natural laboratory for studying the effects of contact between 
racial groups (Dovidio et al., 2003). War conditions often forced the racially segregated forces to integrate in a common goal of survival. As reported in studies of both the U.S. Army (Singer, 1948) and the Merchant Marines (Brophy, 1945), military members who served in integrated situations had more positive interracial attitudes. Patterns in the literature led scholars studying relationships between groups, prejudice, and intergroup to develop a theory of contact (Dovidio et al., 2003). There appeared to be a consensus in the literature that providing information to increase knowledge about minority groups could be beneficial for improving relationships between groups but "programs which aroused feeling are several degrees better than those that rely wholly on cold fact and logic" (Watsun, 1947 from Dovidio, 2003, p. 6). Settings that created face-to-face contact between groups were especially effective at personalizing the experience and arousing feelings.

Studies that looked at racially integrated versus segregated housing further validated the potential of contact. Deutsch and Collins (1951) found that white residents who lived in racially integrated housing settings had more positive attitudes towards racial minorities than white people who lived in segregated settings. This compilation of works, combined with his own views, inspired Allport to construct the theory of intergroup contact.

A social psychologist, Allport studied personality and was particularly concerned with traits of personality and attitudes (Allport, 1935; Darity, 2007). Allport believed that psychoanalysis went too deeply by searching for meaning in each action or statement; and that behaviorism did not delve deeply enough. He posited that attitudes were real elements in human nature that could be measured and studied. Allport's 
interest in intergroup contact was motivated by his work in problem-focused social sciences, the use of evidence and social justice.

Allport believed that prejudice existed in all societies and among all age groups. When a negative attitude toward a person based on an identifiable characteristic was overgeneralized it resulted in prejudice. Prejudice, which contained two elements, attitudes and beliefs, negatively affected interpersonal relationships on many levels. Prejudicial attitudes are evident when a person displays favor to the in-group members and has a disfavor for out-group members. Overgeneralized beliefs extended prejudicial beliefs to entire groups of people as expressed in both behaviors and words (Allport, 1954). Allport also believed that under certain conditions prejudice could be reduced through IGC.

\section{Optimal Conditions}

Allport believed that positive IGC experiences resulted in changes in attitudes, beliefs and behaviors between groups that could be sustained over time (Stephan \& Stephan, 2001). In his seminal work, Allport (1954) described conditions that facilitate the effectiveness of IGC as a means to reduce prejudice and improve intergroup attitudes and beliefs. Working with Allport, one of his protégé's, Thomas Pettigrew refined and titled these as four optimal conditions: 1) equal status, 2) common goals, 3) intergroup cooperation and 4) institutional support (Pettigrew, 1998). As one of Allport's students, Pettigrew studied these conditions at length.

The first condition, equal status can be difficult to define as scholars tend to describe the concept differently. The meaning does not imply that all participants of IGC must have equal status upon entering the IGC situation. Generally, it refers to providing 
all members, regardless of group status, the opportunity to have input during the contact setting (Pettigrew, 1998). All members' opinions and input are equally important. When equal status does not exist between group members during IGC, establishing equal status initially may facilitate positive outcomes (Pettigrew \& Tropp, 2011). In a training setting, establishing equal status includes allowing all members to participate by expressing opinions and making decisions.

The second condition, common goals, is described as helping members of different groups to find ways to work together to achieve shared goals (Pettigrew \& Tropp, 2011). Allport posited that when people must come together to accomplish a task they are more likely to experience changes in attitude. Allport also posited that common goals were more important than equal status in facilitating change.

The third condition is similar to common goals. Intergroup cooperation is described as facilitating an environment where different group members work together cooperatively rather than competitively (Allport, 1979). Removing the between group, competitive element from the IGC situation has been suggested by some to be more beneficial than common goals alone (Dovidio et al., 2003).

Institutional support is the final optimal condition. It is described as efforts from authorities to establish and support norms that promote positive intergroup contact through norms established by actions such as policies, guidelines, practices and enforcement (Allport, 1954; Pettigrew, 1998). It has been shown that institutional support alone can lead to positive outcomes when testing IGC. By supporting the IGC experience, institutions are providing implied institutional support (Pettigrew \& Tropp, 2011) 
The importance and necessity of these conditions continues to be debated (Bernstein \& Swartwout, 2012; Pettigrew \& Tropp, 2011). In the most comprehensive review of the literature related to ICG conducted to date, results show that when any or all of the four conditions are present, prejudice may be more greatly reduced, awareness may increase and attitudes may improve. However, multiple studies show that significant positive effects are also produced when none of the conditions are present and IGC occurs (Pettigrew \& Tropp, 2006; Pettigrew, Tropp, Wagner, \& Christ, 2011).

IGC theory has been used extensively to explore the effects of contact between groups over the last six decades. Since Allport formally framed the concept of IGC in 1954, the amount of attention it has received has increased each decade (Pettigrew \& Tropp, 2006).

\section{Evidence of IGC Theory}

In their meta-analytic test, Pettigrew and Tropp (2006) looked at data from 713 independent samples of IGC studies conducted between 1940 and 2000. Reports from studies conducted in a variety of settings with target groups marginalized by race, ethnicity, immigration status, age, mental illness, physical disability and sexual orientation show positive results. Ninety-four percent of the studies reported a statistically significant decrease in prejudice, measured in a variety of ways, as a result of IGC. The number of studies using IGC continues to increase; between 1990 and 2000 alone, Pettigrew and Tropp secured 180 studies that tested IGC theory. Their metaanalysis included studies from 38 countries that used field, archival, survey and laboratory research approaches. They found that IGC has been effective with reducing prejudice in multiple settings including workplaces and education. 
Not surprisingly, studies show that IGC contact can have strong effects with reducing prejudice at a young age (Pettigrew \& Tropp, 2006). Some of the strongest effects of contact are noted with children less than twelve years of age and in collegeaged adults. These results are consistent with Allport's (1954) original work. Allport posited that by the time young people reached their teenage years of high school their identification with groups was well formed. This is also consistent with research that shows that during young adulthood, or the college years, individuals transform their thinking that can lead to changes in how they think and behave towards outside groups (Henderson \& Murdock, 2012). Allport's interests were primarily related to understanding adults and as he posited, IGC can have positive effects throughout the lifespan (1954).

Multiple studies provide evidence of the effectiveness of IGC with adults. For example, in an IGC study related to sexual orientation with 249 police officers and civilian employees, $60 \%$ of respondents were older than 35 years of age and less than $5 \%$ were below the age of 25 (Bernstein \& Swartwout, 2012). IGC resulted in statistically significant reductions in prejudice towards LG police officers. In the social work discipline, IGC theory was used to explore the effectiveness of a community group of adults that came together to address racial, ethnic and cultural segregation (Rodenborg \& Huynh, 2006). Elements of institutional support, equal status and common goals were described as reasons why the group under study continued to meet after six years while the 14 other groups that formed at the same time, ended after only months. IGC is also shown to be effective in education and training. 
Scholars and educators are beginning to identify the importance of using theory to inform training and the benefits of IGC. IGC contact has been used to inform both the training content and training design. In a healthcare education program, attitudes and perceptions were measured to assess students' reactions to an eight hour interprofessional training session (Mohaupt et al., 2012). IGC theory was used to inform the design and results show that structured IGC between disciplines was effective with improving participants' knowledge, attitudes and perceptions of inter-professional work. In Australia, scholars applied IGC contact to create a positive speaker program. Patients with hepatitis $\mathrm{C}$ spoke to healthcare providers about their experiences of living with a stigmatizing chronic disease (Brener, Wilson, Rose, Mackenzie, \& De Wit, 2013). Qualitative analysis showed that applying the optimal conditions of IGC led to positive changes in attitudes of healthcare providers. Although IGC theory has shown to be effective in a variety of settings and with multiple populations, there are also limitations and criticisms.

\section{Limitations and Criticisms of IGC Theory}

Authors identified selection bias as a potential limitation in studies of IGC theory. Most studies seek volunteer participants, increasing the likelihood that people with higher degrees of prejudice are less likely to participate (Dickey, 2013; Hodson, 2011; Pettigrew, 1998). Selection bias can be problematic in both structured and unstructured IGC settings (Pettigrew, 1998). For example, a person who is highly prejudiced towards sexual minorities is less likely to frequent social events where LG people are the majority. That same person is also less likely to participate in a study related to assessing attitudes towards LG people using IGC, unless required. 
There are also potentially negative effects of IGC and opposing views of IGC altogether. Under stressful or competitive conditions, IGC can have no effect on prejudice or increase prejudice (Pettigrew et al., 2011). To illustrate, Pettigrew, et al., described a soldier and a suspected suicide bomber with opposing goals. In this setting, contact is likely to increase anxiety and prejudice among both parties.

Critics of IGC suggest that contact may reduce individual prejudice but does little to eliminate conflict between entire groups. (Dixon, Durrheim, \& Tredoux, 2005). Others argue that IGC delays social progress because reduced prejudice interferes with inter group conflict, a necessary element for social change (Saguy, Tausch, Dovidio, \& Pratto, 2009). Yet, in structured and unstructured contact, IGC contact continues to show effectiveness and the number of studies using IGC continues to grow.

\section{Evidence of IGC Theory with Sexual Minorities}

Negative attitudes and a lack of awareness of sexual minorities have led scholars to begin to question how care providers will sufficiently meet their needs in a variety of settings. IGC theory is shown to be a valuable approach when examining factors related to understanding and reducing prejudice towards sexual minorities and exploring ways to increase awareness and positive attitudes towards sexual minorities. In their metaanalysis, Pettigrew and Tropp (2006) found that when compared to other marginalized groups, the effects of IGC were significantly greater when the target group is gay men and lesbians $(r=-.27)$. This significant difference held even when the results for other target groups were combined (mean $r=-.21$ ). Similar positive effects of IGC have been substantiated in the results of meta-analysis that looked only at the cases related to lesbians and gay men (Smith, Axelton, \& Saucier, 2009). 
The meta-analysis included data from 41 studies and more than 12,000 cases. Eighty-three percent of cases came from studies conducted in the United States. The effects of IGC were statistically significant across multiple measures including the Attitudes Towards Lesbians and Gays Scale, the Index of Attitudes Towards Homosexuality and the Homosexuality Attitudes Scale (Smith et al., 2009).

Length and frequency of contact can influence the effects of IGC. Not surprisingly many studies show that the more frequent the contact with an LG person the greater the reduction in prejudice (Herek \& Capitanio, 1996; Pettigrew \& Tropp, 2011). Though they did not look at the length or frequency per se as a variable, Smith et al. (2009) looked at differences between correlational $(r=-.25)$ and experimental studies $(r$ $=-.26$ ). They suggest the insignificant difference in results of this collective analysis implied that both limited contact and extended contact are nearly equally effective in reducing the level of prejudice towards lesbians and gay men. Results of a study with 122 undergraduate university students support these findings. This experimental study found positive effects of IGC with strangers with only one hour of contact and subtle disclosure of sexual orientation is introduced (Graham, Frame, \& Kenworthy, 2014). Demographic, social and cultural influences can also impact individuals' beliefs related to sexual minorities.

\section{Previous Contact}

As described by Allport (1954), contact, whether structured or unstructured can influence participants responses. Not surprisingly, and consistent with IGC, the strongest predictor of favorable attitudes toward sexual minorities is contact with sexual minorities 
outside of the study (Herek \& McLemore, 2013; Pettigrew \& Tropp, 2006). This is shown to be true across multiple age groups and in a variety of settings.

High school students who reported LG friends also reported more favorable attitudes towards sexual minorities in general (Heinze, 2009). In a cross sectional study conducted with only certified nursing assistants who had a mean age of 40 , respondents who reported acquaintance with an LG person reported significantly less negative attitudes towards LG than respondents who did not have acquaintance with LG people (Dickey, 2013). Previous contact is reported to have even stronger positive effects if it included dialogue about the meaning of identifying as a sexual minority (Herek, 2007). The effects of previous contact have also been reported when the contact was not direct. In a review of the literature focused on exploring the effects of IGC with the most intolerant, both direct and indirect contact had positive effects on attitudes towards outgroup members (Hodson, 2011). Participants who had other in-group members who reported positive contact with out-group members reported more positive attitudes towards the out-group. There are also variables that are associated with negative attitudes towards sexual minorities.

\section{Religiosity}

The inclusion of factors that measure religiosity is important when studying IGC related to sexual minorities. In his development of the IGC theory, Allport (1954) noted that historically it was religion that was the basis for most prejudice. Sexual prejudice and opposition to inclusion of sexual minorities can be especially difficult to address when based in religious ideology. Individuals who use religious beliefs to avoid or exclude sexual minorities base their argument in a moral stance rather than viewing it as 
discrimination (Herek \& McLemore, 2013; Rosik, 2007). The IGC optimal condition of institutional support is important to consider when exploring the relationship between attitudes towards sexual minorities and religiosity. Religiosity becomes problematic in service delivery when morality, based in religion, is used to deny people care, negatively impact treatment or impose judgment through practices and policies that impact sexual minorities.

Like other practices (e.g., divorce, birth control) that are based in religious morality, individuals also disregard the religious teachings to practice personal beliefs. This is also evidenced in the literature related to attitudes towards sexual minorities. Many religious organizations hold positive attitudes towards sexual minorities. In a study with high school students, adolescents who reported identifying as a sexual minority as wrong, were likely to base their judgment in religious morality (Heinze, 2009). Interestingly, respondents from the same sample that reported favorable attitudes towards sexual minority peers also justified their views with religious beliefs such as the moral obligation to treat others as you wish to be treated.

Though laws in America are changing in support of mistreatment of sexual minorities as discrimination based in prejudice rather than moral stance (Herek \& McLemore, 2013), religiosity remains the strongest predictor of negative attitudes (S. J. Smith et al., 2009). This predictor has been shown to be true with both adolescents between the ages of 14 and 18 (Heinze, 2009) and with adults when most of the sample is above the age of 35 years (Bernstein \& Swartwout, 2012). The relationship remains when religion is measured in multiple ways such as degree of religiosity, literal belief of 
the Bible (for Christianity), or attendance at religious services (Herek \& McLemore, 2013).

\section{Gender}

Studies related to attitudes about sexual minorities have shown that gender may effect respondents' perceptions in two ways. First, research shows that heterosexual men and women have differing attitudes towards sexual minorities in general. Secondly, there are differences in respondents' attitudes when the subject is gay men versus lesbians (Herek, 2000; Herek \& McLemore, 2013).

These differences can be explained by considering the concept of in-group affirmation described in IGC theory. Herek (2013) posits that more negative attitudes held by males towards sexual minorities' stems from the need for men to continually affirm their masculinity. Because openly gay men or men perceived to be gay are stereotyped as less masculine, other men assert their in-group affiliation of the male stereotype by expressing negative attitudes towards gay men. Expressing acceptance of sexual minorities, particularly gay men, has risks with in-group affiliation. Favorable attitudes towards gay men may lead to questioning of their own sexual orientation by other in-group members. The same risks are not associated with expressing favorable attitudes towards lesbians. As a result of differences in attitudes by gender, countering negative attitudes towards gay men may be more difficult than countering negative attitudes towards lesbians. Results of meta-analysis indicated that effects of IGC, though statistically significant for both groups, are greater for lesbians $(r=-.30)$ than gay men $(r$ $=-.27$ (S. J. Smith et al., 2009). Individual studies, however, are less decisive. 
Reviews of individual studies reveal inconclusive evidence related to gender as a predictor. Factors such as age and institutional support may be more influential than gender. For example, Bernstein (2012) found that although female police officers were more likely to expect that LG police officers would be accepted in the workplace, there were no statistically significant differences by gender in actual rates of acceptance of fellow LG officers. On the other hand, the study with high school students revealed that female adolescents were significantly more likely to report favorable attitudes towards LG peers than male adolescents (Heinze, 2009). Female adolescents were also significantly less likely to tease or exclude LG peers when compared to their male peers.

\section{Provider Beliefs, Attitudes and Perceptions of LG Older Adults}

Until recently, information on service provision with older sexual minorities was nearly invisible in gerontological literature (Knochel et al., 2011). There is now a small but growing body of literature related to assessing the beliefs, attitudes and perceptions of providers that addresses service delivery with older sexual minorities. Reviews of this literature revealed that LTC providers' negative attitudes of older sexual minorities may have negative impacts on service delivery (Bell et al., 2010; Hinrichs \& Vacha-Haase, 2010; IOM, 2011; Knochel, Croghan, Moone, \& Quam, 2012).

LTC staff receive little training to dispel myths about older sexual minorities or training to develop awareness or skills related to serving older sexual minorities. This is shown to be an issue in both national studies and local studies in areas where sexual minorities are more established. In a national cross sectional survey, with 1,071 LTC social services directors only $24 \%$ had received training related to homophobia in the five years prior to the survey (Bell et al., 2010). In a qualitative study of LTC providers in an 
area of Denver with a known high population of sexual minorities, only 4 of 29 agencies reported that their staff were trained as highly qualified to serve sexual minorities (Portz et al., 2014). In a national survey of Area Agencies on Aging directors, Knochel et al. (2012) found that even though $81 \%$ of respondents reported a willingness to provide training related to serving sexual minorities only $34 \%$ had actually offered training to work with this population of older adults. Offered meant that staff could attend but were not required to attend training related to serving sexual minorities. Agencies located in rural areas were significantly less likely to have provided training or report a willingness to provide training related to serving sexual minorities.

Though the body of literature is growing, there is a lack of studies that utilize theory or standardized measures to examine the attitudes of caregivers. Of the 13 studies reviewed related to examining the attitudes of care providers, only three identified a theoretical frame to inform their work. Studies that used a theoretical frame were focused on the following: developing a measure using clinical measure theory (Crisp, 2006); a qualitative driven rapid assessment using cultural competence theory (Portz et al., 2014); and a single study that focused on provider attitudes using anti-discrimination theory (Dickey, 2013). The findings of this review are consistent with the position identified by Paluck (2006) who suggested that the social sciences continue to overlook an opportunity to apply theory to studies related to understanding the treatment and perceptions of marginalized groups such as older sexual minorities.

Of the 13 studies reviewed, most did not utilize a standardized measure even though many studies measured similar constructs for which standardized measures existed. Using a standardized measure can help to communicate the importance of a 
social issue and increase generalizability (Morgan, 2014). One study included in this review (Sherman, Kauth, Shipherd, \& Street, 2014) utilized the Attitudes Toward Lesbians and Gay Scale (ATLG), a commonly used measure tested in a variety of settings. Another article, (Crisp, 2006) served as a report of a newly developed measure to assess providers beliefs related to serving LG populations.

Reports show that nursing assistants provide $85 \%$ of the direct care in LTC facilities (Schirm, Albanese, Garland, Gipson, \& Blackmon, 2000); however, few studies have examined these employees' attitudes towards sexual minorities. Direct care positions such as nursing assistants in LTC settings may be the most difficult to reach with research even though they have the most personal interaction and direct impact on quality of care. In a single study with only nursing assistants $(n=116)$, Dickey (2013) found moderate levels of homophobia among respondents working in LTC facilities. Consistent with IGC theory, respondents who reported acquaintances with an LG person had significantly lower levels of homophobia than those who did not report LG acquaintances. An unusually high proportion of respondents in this study, 77\%, reported acquaintance with an LG person. The study did not measure religiosity, the strongest predictor of negative attitudes towards sexual minorities.

There is no information on the role or use of IGC theory with training LTC care providers. There is, however, limited research that shows that LTC providers' attitudes towards sexual minorities can negatively impact care delivery. There is a need to explore interventions that incorporate applicable theory and evaluate effectiveness with standardized measures. 


\section{Conclusion}

Research shows that interventions that focus on increased awareness and knowledge are moderately effective; and adding the element of IGC contact can extend effects (Pettigrew et al., 2011). Consistent with the literature related to storytelling, personal contact influences other mediating factors by helping participants sense how the marginalized group sees the world (Allport, 1954).

This section served as a review of the literature related to the factors of interest identified in the purpose of this research in Chapter One. As evidenced by this literature review, there are areas of need and gaps related to understanding LTC providers towards attitudes towards sexual minorities. There also exists a need to test interventions designed to increase awareness and improve attitudes towards LG older adults. However, developing an intervention related to increasing awareness that is effective at reaching the target audience of direct care staff within training time constraints and limited resources can be challenging.

Results of the literature review reiterate that as social work researchers and providers of care, we must find resourceful and creative ways to increase awareness of older LG adults at risk of marginalization in LTC facilities. Chapter Three provides a description of the research design and methodology for this study that expands the current literature. 


\section{CHAPTER THREE: RESEARCH DESIGN AND METHODS}

Chapter Two provided a review of the literature related to IGC, attitudes of LTC staff towards older LG adults and other variables. Building on the material from the literature review, this chapter provides information on the design of the current study. First, the research design is described followed by a description of the targeted population. Measurement instruments are reviewed followed by the operationalization of variables and a description of the data collection process. Finally, statistical and qualitative data analysis methods are described.

\section{Research Design}

For this study a single group, pretest-posttest design utilizing quantitative and qualitative approaches was utilized. In mixed methods research many approaches can be employed to collect, analyze and report both quantitative and qualitative data (Creswell \& Clark, 2011). In the embedded style used here, the primary approach drives the study and the secondary approach is used to complement the primary approach (Creswell \& Clark, 2011). As presented in the organization of the research questions in Chapter One of this document, quantitative analysis drives this research project.

Figure 2 illustrates how quantitative data was collected prior to the intervention with study participants. During the intervention, qualitative data in the form of audio recordings of the group discussion were collected. Following the intervention, quantitative data was again collected from participants in the form of survey questions and qualitative data in the form of open-ended survey questions. The group discussion, detailed in the data collection section of this chapter, is included as part of this study to collect qualitative data not captured in the survey. The discussion also served as a 
debriefing process for participants and allowed participants the opportunity to ask questions, explore reactions to the information presented in the story, and to qualitatively explore the influence of storytelling on attitudes toward LG older adults.

Figure 2. Embedded QUAN (+qual) design
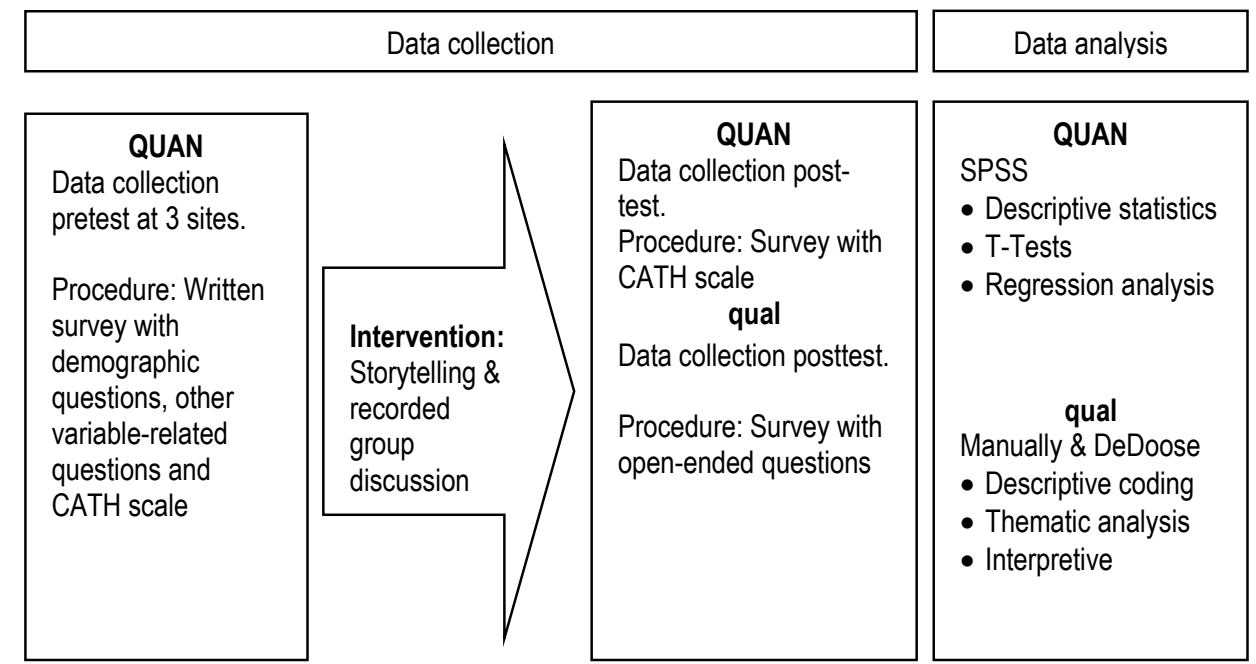

Reporting

QUAN + qual Report of pre \& post QUAN findings, qual findings and integrated report of QUAN \& qual finding to answer research questions \& directional hypothesis

This embedded $Q U A N(+q u a l)$ design is used for this study for several reasons. The embedded approach is helpful when exploring emerging issues (Creswell \& Clark, 2011) such as issues related to serving LG older adults (IOM, 2011). Both qualitative and quantitative data are also helpful when studying influences of staff training interventions (Williams, 2007). Williams found that collecting both forms of data allows for measuring change and capturing unanticipated findings and comprehensive details that one method alone does not detect. Qualitative data can be used to further explore and explain quantitative findings (Creswell \& Clark, 2011) and any emerging themes can be identified. In this study, qualitative methods are used to capture information related to 
participants' reactions to the storytelling event, data to supplement participants' quantitatively measured attitudes toward LG older adults and explore emerging themes related to this topic. Finally, employing multiple methods can reduce the effects of social desirability, a threat in survey research. Comparing data in multiple formats (i.e., quantitative survey questions, the recorded interview and open ended questions) reduces the possibility that participants answered questions to appeal to researchers or other participants (De Leeuw \& Hox, 2008).

\section{Target Population and Sample}

The target population for this study included any staff member that worked in a LTC facility. The goal was to obtain a sample representative of the makeup of a LTC facility. This includes administrators, social workers, nursing staff, support staff, activities directors, and nursing assistants (or staff by other titles that provide the largest amount of direct care to residents).

To implement this study, first sites were recruited. To recruit sites for participation, information about this study was presented at a quarterly meeting of The Quality Improvement Program for Missouri's Long-Term Care Facilities (QIPMO) nursing team. QIPMO nurses who visit LTC providers in central Missouri also shared information about the study with LTC facility administrators. When facility administrators expressed interest in participation, the primary investigator for this study contacted them via phone or followed up with onsite visits to provide additional information.

When a commitment was received from sites to participate, efforts to recruit participants commenced. To recruit participants at potential sites, a flyer was distributed 
to administrators of LTC facilities (see Appendix A). The administrators were asked to share information with employees at staff meetings preceding the proposed research project event and post the flyers in employee areas of the facility. As indicated on the flyer, employees were informed of the purpose of the study and informed that participation was voluntary. The flyer also contained the contact information for the primary researcher and informed LTC staff that participants were eligible to receive a gift card in the amount of $\$ 20$ for their contribution.

\section{Eligibility Criteria and Sampling Inclusion}

LTC staff from three sites were included in this study. To be considered for inclusion, sites had to be providers of LTC (assisted living, nursing home, etc.) and individual participants had to be employed in a LTC facility. Individuals were required to be over the age of 18 and required to consent in writing to participate. In an incentive to increase participation, individuals received a $\$ 20$ gift card.

\section{Sample Size Estimation}

A statistical power analysis was performed for sample size estimation based on data from previous studies (LaMar \& Kite, 1998; Wilkinson, 2006, 2008). With an alpha $=0.05$ and power $=0.80$ the projected sample size for this study to estimate a medium effect size of 0.5 (Cohen, 1988, 1992) was $\mathrm{N}=28$ pairs to compare pretest and posttest mean scores within group. To complete a multiple regression with 4 predictors and assuming .03 correlation with the dependent variable, power $=0.8$ and alpha $=0.05$, it was estimated that an $\mathrm{N}=55$ is needed. The target sample size of 60 was estimated to be adequate to explore the main objective of this study - the impact of the intervention and 
allow for the additional regression analysis to explore relationships between multiple variables.

\section{Instrumentation}

This study was conducted using an instrument administered at pretest (see Appendix B) and posttest (see Appendix C). Demographic data, information related to religiosity and previous acquaintance with an LG person was collected only at pretest. Attitudes towards LG older adults was collected using the same instrument at pretest and posttest. As shown in appendix C, the posttest contained open-ended questions that provided participants with the opportunity to qualitatively express views about the subject matter.

\section{Operationalization of Variables}

Table 1 provides a summary of how each variable was operationalized, measured and coded for statistical analysis. This study has a single dependent variable, attitudes towards LG. The independent variable is religiosity. Regression analysis also controls for previous acquaintance with an LG person as operationalized in Table 1 and age of respondents.

Attitudes towards LG. Attitudes toward LG older adults is the single dependent variable in this study. There are a large number of instruments designed to measure beliefs, attitudes and perceptions related to serving sexual minorities, making the selection of a single standardized instrument difficult. A systematic review of instruments related to assessing these constructs identified 115 studies that utilized 47 different instruments between 1993 and 2010 (Costa, Bandeira, \& Nardi, 2013). Assessing the influence of competency, skill and awareness training designed to reduce 
negative attitudes has been measured in many ways. Even though researchers often examined the same or similar constructs they frequently developed different measures rather than using

Table 1.

Operationalization and Measurement of Variables

\begin{tabular}{|c|c|c|c|}
\hline Variable & Operationalization & Measure & Coding \\
\hline $\begin{array}{l}\text { Attitudes } \\
\text { toward LG } \\
\text { older adults } \\
\text { (dependent } \\
\text { variable) }\end{array}$ & $\begin{array}{l}\text { Participants } \\
\text { perceptions about } \\
\text { LG }\end{array}$ & $\begin{array}{l}\text { The CATH (Lamar \& Kite, } \\
\text { 1998) a } 20 \text { item scale. } 10 \text { items } \\
\text { measure attitudes towards } \\
\text { lesbians and } 10 \text { items measure } \\
\text { attitudes towards gay men on } 5 \\
\text { point Likert like scale from } 1 \\
\text { (strongly disagree) to } 5 \\
\text { (strongly agree). }\end{array}$ & $\begin{array}{l}\text { Composite range: } 20-100 . \text { Items } \\
3,4,6,9,13,14,16,19 \text { reverse } \\
\text { scored and recoded to same } \\
\text { direction. Continuous measure } \\
20=\text { extremely negative attitude. } \\
100=\text { extremely positive } \\
\text { attitude. Lesbian and gay men } \\
\text { factor composite range } 10-50 .\end{array}$ \\
\hline $\begin{array}{l}\text { Religiosity } \\
\text { (independent } \\
\text { variable) }\end{array}$ & $\begin{array}{l}\text { Self-reported } \\
\text { degree of } \\
\text { religiosity. }\end{array}$ & $\begin{array}{l}\text { How religious are you? Not at } \\
\text { all, somewhat, not very, very. }\end{array}$ & $\begin{array}{l}\text { Ordinal variable. Ranked } 1 \text {-not } \\
\text { at all religious to } 4 \text {-very } \\
\text { religious. }\end{array}$ \\
\hline $\begin{array}{l}\text { Contact with } \\
\text { LG people } \\
\text { (control } \\
\text { variable) }\end{array}$ & $\begin{array}{l}\text { Acquaintance } \\
\text { with an LG } \\
\text { person }\end{array}$ & $\begin{array}{l}\text { Acquaintance is measured } \\
\text { separately for LG. Do you have } \\
\text { any lesbian [gay] friends? } \\
\text { Response options include yes } \\
\text { or no. }\end{array}$ & $\begin{array}{l}\text { Previous contact }=1, \text { No } \\
\text { previous contact }=0 \text { (reference } \\
\text { group). }\end{array}$ \\
\hline
\end{tabular}

existing instruments. For example, Hughes, Harold, and Boyer (2011) developed a set of survey items to measure opinions, preparedness, awareness and training needs related to serving LBGT older adults to assess providers in the state of Michigan. Similarly, Porter and Krinsky (2014) developed a set of survey questions to measure similar constructs related to the effectiveness of an LGBT cultural competency training designed to increase awareness and improve attitudes, beliefs and perceptions. Costa, et al., concluded that finding an existing scale can be difficult yet creating a new scale may not be necessary. 
The adaptation of scales that take into consideration the setting and the purpose of the study are possible solutions to measuring constructs of interest.

To measure attitudes toward LG older adults in this study, the Components of Attitudes Toward Homosexuality Scale (CATH; Lamar \& Kite, 1998) was used. The CATH was selected for several reasons. It is a multidimensional measure that contains four components: condemnation, morality, contact and stereotypes that can be used independently. In an effort to minimize the amount of time required to complete the survey, only the morality component was used in this study. The CATH morality component was also selected because it is shown to be a valid and reliable measure and can be used to separately measure attitudes towards lesbians and gay men.

The CATH morality component consists of 10 items related to attitudes towards lesbians and 10 items related to attitudes towards gay men measured on a five point Likert like scale. As outlined in Table 1, results were combined to create a composite measure. Lower ratings indicate more negative attitudes and higher ratings more positive attitudes.

In the original development of the CATH, Cronbach's alpha was reported as .93 for lesbian morality and .92 for gay male morality (LaMar \& Kite, 1998). Studies that have utilized the CATH report similar internal consistency coefficients. A study using the combined LG morality component reported Cronbach alpha of .90. In two studies that explored attitudes towards lesbians, the Cronbach alpha for the lesbian morality component was .88 and .85 (Wilkinson, 2006, 2008).

Religiosity. As noted in Chapter Two of this paper, there are several indicators that have been operationalized to measure religiosity in studies assessing attitudes 
towards sexual minorities. In an effort to minimize the size of the measure to accommodate time constraints, religiosity was measured by asking respondents about the degree of their religiosity: How religious are you (McDermott \& Blair, 2012)? Four response options ranged from "not at all" to "very".

Previous Acquaintance with LG people. Previous studies have measured the variable of previous contact with LG people by asking binary questions about friendships and relationships (Heinze, 2009; Hodson, 2011). Following that model, in this study, two questions were asked: Do you have any lesbian friends and do you have any gay friends? Participants could respond either yes or no to each.

\section{Data Collection}

Data for this study was collected during April and May 2015. All data was collected in hard copy form. To assist with managing the data collection process, organizing the setting, and collecting observational data, a research assistant was utilized. Details about the role of the research assistant are outlined in Appendix D, Role of Notetaker and Observer. Prior to the intervention, participants were asked to review and sign the consent form (Appendix E). Participants were then asked to complete preintervention questions that included demographic information and measure of attitudes towards LG (see Appendix B). Upon completion of the intervention, participants took part in a group discussion that was audio recorded.

Using the group discussion guide (Appendix F), the primary researcher facilitated the group discussion. The guide was used to stimulate discussion and also allowed for informal discussion between participants. Utilizing a guide to aid in the facilitation of group discussion can assist in the reduction of the possibility of researcher bias (Yin, 
2010). The research assistant ensured that the event was audio recorded (Appendix D). The research assistant also made observations during the group discussion about the physical setting, interactions between members and the primary research, non-verbal behaviors and captured specific quotes.

As part of the introduction, participants were reminded that participation was voluntary and information being recorded. Participants were asked to not use their names and the names of other participants. A set of five questions were used to guide the start of the discussion and ensure the discussion covered areas related to the content of the study. It is important in qualitative work involving group interactions to frame questions in a manner that is not leading (Yin, 2010). As shown on the group discussion guide, statements such as "tell me more about that" was used to seek clarification and solicit additional information. It is also important to consider how individual participants may dominate a group discussion or how a single item may dominate the discussion.

Questions such as "do others have a point of view they would like to share" were used to facilitate a more broad discussion and encourage participation (Appendix F).

Immediately following the group discussion, participants were asked to complete the post-intervention survey (see Appendix C). The post survey included the CATH attitudes towards LG questions used in the pre survey, and open-ended questions. The open-ended questions were included as part of the post-survey to allow participants the opportunity to express qualitative reactions that they may not be comfortable sharing during the group discussion or did not have the opportunity to express.

In an effort to protect privacy, while also ensuring the ability to measure change in scores associated with other variables of interest, participants were given a number on 
an index card ranging from 1 to $\mathrm{n}$ ( $\mathrm{n}$ represents the number of people in the training). Participants were asked to record that number in the upper right hand corner of both the pretest and posttest surveys. Upon completion of the posttest survey, numbered index cards were collected and participants received a gift card.

\section{Intervention}

The development of the intervention was guided by IGC theory and was designed to bring together LTC staff with older persons that identifies as LG via video. As posited by Allport (1954), action research in the form of structured contact and acquaintance programs can be effective with improving relationships between groups. The intervention also attempted to communicate the human element on a personal level; as stated by Allport: "The deeper and more genuine the association, the greater its effect" (p. 489). This modality and design was selected in an effort to reach the majority of staff, including those who provide the greatest amount of direct patient care. The creation of an intervention that reached the majority of the staff required the development of a module that accommodated the time constraints of LTC providers' on-site staff meeting times which was limited to approximately one hour from start to finish.

\section{Storytelling}

The intervention for this study was a storytelling event presented in the form of a video-recorded, first person, life history. The primary researcher on this project worked with an older lesbian woman and an older gay man to chronicle their life stories and collaboratively developed their stories into a video documentary for sharing with LTC staff. The guide used for developing their stories is included as Appendix G. The overarching objective was to communicate the impact of marginalization over the 
lifetime on some LG people from the perspective of the storyteller's personal experiences. Their stories were grounded in their individual experiences as a sexual minority who lived during a period when same-sex behavior was highly criminalized and formally categorized as a mental illness. Storytellers shared their recollection of major events in the LG civil rights movement such as the Stonewall riots of 1967. Storytellers also shared how identifying as a sexual minority impacted work life, personal relationships with family and interactions with service providers including healthcare workers. Videotaped interviews were edited with the goal of limiting the final product to 20 minutes maximum to allow time for the consenting process, time for the group discussion that followed the video, and adequate time to complete the pretest and posttest surveys.

\section{Data Analysis Plan}

\section{Quantitative Data Analysis}

All quantitative data analysis was completed using SPSS Software, Version 21 (IBM Corporation, 2012). Demographic characteristics of respondents and baseline data about attitudes towards LG were analyzed using univariate methods including means, standard deviations, frequencies and percentages as appropriate. Inferential statistics were used to answer hypothesis for Research Questions One and Two. The paired t-test was used to assess differences in attitudes between pre intervention and post intervention.

Multiple linear regression was used to answer Research Question Three and test the hypothesis. A regression was run on attitudes towards LG and religiosity while controlling for previous acquaintance with LG, and age. Missing data were addressed by 
using the pairwise function in SPSS. Cases with missing data for a specific variable were omitted from analysis that included the specific variable.

\section{Qualitative Data Analysis}

Qualitative data collected during this study was used to supplement quantitative findings and identify emerging themes. Research Question One contains embedded qualitative components. Qualitative data consists of written responses to open ended questions on the post storytelling survey, audio-recorded group discussions following the storytelling, field notes and memos completed during the data review and analysis process.

As identified in Research Question Two, the qualitative analysis focused on exploring how storytelling influences LTC staff member's attitudes toward LG older adults and identifying emerging themes. The qualitative analysis was managed manually. Audio recordings from the group discussions were transcribed, double-spaced with two inch margins throughout, and printed in hard copy. The area afforded by large margins and double-spacing allowed ample space for capturing written notes during the manual portion of qualitative analysis.

Several types of coding were considered to identify coding methods that align with the research question and the qualitative approach of this study (Saldaña, 2013). Three phases of analysis were utilized for analyzing qualitative data. These techniques were selected because each aligned well with the grounded theory approach and the qualitative research questions in this embedded study design.

In the first stage of analysis, the transcribed group discussions, responses to open ended questions, field notes and research memos were explored by reading through all 
materials. Additional research memos were completed and then the first round of coding was completed (Creswell \& Clark, 2011). An eclectic mixture of provisional, versus, invivo and emotional coding was applied (Saldaña, 2013). This combination of coding methods allowed for capturing a wide variety of data and established the foundation for more detailed analysis. The provisional coding aided in connecting the data to the terms associated with IGC theory. The versus coding technique captured conflicting views of participants. In-vivo coding captured terminology used by participants in reaction to the material and delivery of the intervention. And, finally, in this first round of analysis, emotion coding aided in identifying participants' passionate responses.

Process coding was selected for second round coding because it is used in grounded theory approaches to capture emerging themes and it is considered a good approach for exploring interactions of participants and exploring how people respond to information (Saldana, 2013). In the third phase, thematic analysis was applied and interpretations of the data was completed.

Codes from the descriptive coding analysis were reviewed and manually categorized into larger themes. Also referred to as theming the data, in qualitative analysis, themes emerge as a result of the process of coding and analytical reflection (Saldaña, 2013). Whereas the other codes were concerned with topics, themes were used as a means to categorize recurring topics in an organized manner. Thematic analysis also provided the opportunity to understand the qualitative data in a more profound manner. These approaches were utilized for this study because each was conducive to exploring topics for which there is limited information and the approaches are shown to be a 
beneficial method for exploring beliefs and attitudes (Richards \& Morse, 2013; Saldaña, 2013).

Validation of qualitative findings. In an effort to validate qualitative findings, results were reviewed with the research assistant who assisted with the survey process and made observations during the intervention. Finally, exploring and reporting disconfirming evidence was included as an additional method to validate findings (Creswell \& Clark, 2011).

\section{Summary and Proposed Reporting of Results}

This chapter provided a thorough description of the research design, target sample, data collection and plan for data analysis. The mixed method design utilized quantitative and qualitative approaches creating assets that can be maximized to enhance the understanding of the topic of study. It is important to consider how findings from both sources of data were linked.

Enhancing the understanding includes reporting on findings that are congruent and findings that infer inconsistency in the results. The opportunity to explore findings that both align and inconsistencies is a strength of conducting mixed methods research that is not usually captured when using a single method (Teddlie \& Tashakkori, 2009). 


\section{CHAPTER FOUR: RESULTS}

Informed by intergroup contact (IGC) theory, this study explored how IGC contact in the form of storytelling influences long-term care (LTC) staff members' attitudes toward LG. Data was gathered from employees who work in LTC settings in central Missouri. Sixty LTC staff members participated in the intervention. All data was collected in face-to-face settings. Quantitative data was collected in the form of hard copy surveys. Qualitative data was collected via audio recorded group interviews and with open-ended questions on the post-survey form. In this chapter, a description of the sample is presented followed by the results of the analyses utilized to answer the three research questions.

\section{Pre Analysis and Description of Sample}

SPSS, Version 22 was used to complete quantitative analysis. Pairwise deletion was used to address missing data. Sixty participants completed the surveys for this study. As reported in Table 2, the mean age of participants was 38 years, and on average they have 11 years of work experience in LTC and 4 years with their current employer. The majority of participants were female $(n=48,81 \%)$, identified racially as white/Caucasian $(n=43,83 \%)$, almost half worked in the capacity of a certified nursing assistant (CNA, $\mathrm{n}=25,42 \%)$ and about one-third of the sample $(\mathrm{n}=21,35 \%)$ identified certificate as their highest level of education. Among the 57 participants that reported religiosity, scores ranged from 1 (not at all religious) to 4 (very religious) with a mean rating of 2.88 (SD .93). The majority of participants $(n=55,93 \%)$ reported previous acquaintance with an LG person. 
Table 2

Demographic and Background Characteristics of Participants

\begin{tabular}{|c|c|c|}
\hline Variable & & \\
\hline & Mean & SD \\
\hline Age, mean $(n=57)$ & 35.42 & 13.44 \\
\hline Years working in LTC $(n=58)$ & 11.40 & 11.04 \\
\hline Years at current job $(n=59)$ & 4.36 & 5.97 \\
\hline \multirow[t]{2}{*}{ Religiosity $(n=49)$} & 2.88 & 0.93 \\
\hline & $\mathbf{N}$ & $\%$ \\
\hline \multicolumn{3}{|l|}{$\operatorname{Sex}(n=59)$} \\
\hline Females & 48 & 81.40 \\
\hline Males & 11 & 18.60 \\
\hline \multicolumn{3}{|l|}{ Race/ethnicity $(\mathrm{n}=53)$} \\
\hline African American/Black & 5 & 9.40 \\
\hline Caucasian/White & 44 & 83.00 \\
\hline Hispanic/Latino & 3 & 5.70 \\
\hline Pacific Islander & 1 & 1.93 \\
\hline \multicolumn{3}{|l|}{ Education $(n=59)$} \\
\hline HS or GED & 14 & 23.3 \\
\hline Some College & 2 & 3.30 \\
\hline Certificate & 21 & 35.0 \\
\hline AS & 8 & 13.30 \\
\hline $\mathrm{BS}$ & 7 & 11.70 \\
\hline MS & 7 & 11.70 \\
\hline \multicolumn{3}{|l|}{ Job Title $(n=59)$} \\
\hline Activities & 3 & 5.00 \\
\hline Admin Support & 5 & 8.50 \\
\hline Administrator & 2 & 3.40 \\
\hline $\mathrm{C} \mathrm{N} \mathrm{A}$ & 25 & 42.40 \\
\hline Food Services & 3 & 5.00 \\
\hline LPN & 5 & 8.50 \\
\hline Nurse Manager & 2 & 3.40 \\
\hline $\mathrm{RN}$ & 6 & 10.20 \\
\hline Social Work/Social Services & 7 & 11.90 \\
\hline Speech Therapy & 1 & 1.70 \\
\hline \multicolumn{3}{|l|}{ Previous Acquaintance with LG } \\
\hline Yes & 55 & 93.20 \\
\hline No & 4 & 6.80 \\
\hline
\end{tabular}


The Components of Attitudes Toward Homosexuality (CATH) scale was used to measure participants' attitudes towards LG older adults. It consists of two subscales resulting in three measures: attitudes toward lesbians, attitudes toward gay men, and attitudes toward LG combined. As noted in Chapter Three of this paper, one-half of the items on the CATH were negatively worded and one-half were positively worded in an effort to decrease extreme response bias. Prior to conducting analysis, SPSS was used to transform the reverse keyed items. Negatively-keyed items were reversed scored so that all items were positively keyed. Scores for the subscales and overall scale were then computed using pretest data.

For each of the two subscales (i.e., attitudes toward lesbians and attitudes toward gay men), the possible composite range of scores was 10-50. Ten is indicative of a highly negative attitude and 50 is indicative of a highly positive attitude. The attitudes towards lesbians ( 10 items, $\alpha=.79$ ) and attitudes toward gay men (10 items, $\alpha=.89$ ) subscales had high levels of reliability. The possible composite range of scores for the overall measure was $20-100$ with 20 being indicative of a highly negative attitude toward LG and 100 is indicative of a highly positive attitude toward LG. The overall measure of attitudes toward LG (20 items, $\alpha=.91)$ had excellent reliability.

Table 3 provides additional information about each of the subscales and the overall measure of attitudes at pretest and posttest and the difference scores. On average, at pretest, attitudes scores towards lesbians $(\mathrm{M}=42.33, \mathrm{SD}=6.65)$ were higher than attitude scores to gay men $(M=40.91, S D=9.06)$. Attitudes toward lesbian scores $(M=$ 43.64, $\mathrm{SD}=6.59)$ and attitudes towards gay men scores $(\mathrm{M}=42.96, \mathrm{SD}=7.43)$ 
increased on the post-test. Accordingly, attitudes towards the combined LG scores

increased from pre-test $(M=83.55, S D=14.36)$ to posttest $(M=87.00, S D=13.49)$.

Table 3

Descriptive Statistics for Attitudes Toward Lesbians and Gay Men

\begin{tabular}{lcccc}
\hline \multicolumn{1}{c}{ Variable } & Minimum & Maximum & Mean & SD \\
\hline Pre-Test & & & & \\
Attitudes toward lesbians $(\mathrm{n}=55)$ & 24 & 50 & 42.33 & 6.65 \\
Attitudes toward gay men $(\mathrm{n}=55)$ & 10 & 50 & 40.91 & 9.06 \\
Attitudes toward LG $(\mathrm{n}=53)$ & 46 & 100 & 83.55 & 14.36 \\
Post-Test & & & & \\
Attitudes toward lesbians $(\mathrm{n}=56)$ & 26 & 50 & 43.64 & 6.59 \\
Attitudes toward gay men (n=54) & 24 & 50 & 42.96 & 7.43 \\
Attitudes toward LG (n=53) & 54 & 100 & 87.00 & 13.49 \\
Difference scores: post minus pre & & & & \\
Attitudes toward lesbians (n=53) & -6 & 10 & 1.13 & 2.77 \\
Attitudes toward gay men (n=52) & -6 & 14 & 1.88 & 4.09 \\
Attitudes toward LG (n=49) & -12 & 23 & 3.12 & 5.34 \\
\hline
\end{tabular}


To calculate the difference scores, pretest scores were subtracted from posttest scores. Changes in attitudes towards lesbian scores ranged from -6 to 10, and on average scores increased by 1.13 points $(\mathrm{SD}=2.77)$. Changes in attitude toward gay men scores ranged from -6 to 14 and on average scores increased by 1.88 points $(\mathrm{SD}=4.09)$.

Differences in pretest and posttest scores on attitudes towards LG ranged from -12 to 23 and on average, increased by 3.12 points $(\mathrm{SD}=5.34)$.

Pretest and posttest scores are used to answer the quantitative portion of Research Question One: How does storytelling influence LTC staff members' attitudes towards LG older adults? The difference scores are used to answer Research Question Two: How does storytelling influence male and female participants' attitudes towards LG differently? Finally, pretest scores of attitudes towards LG are used in the regression model to answer Research Question Three: What is the relationship between religiosity and attitudes towards LG older adults among participants?

\section{Research Question \#1}

Research Question One is: How does storytelling influence LTC staff members' attitudes towards LG older adults? This question is answered with quantitative and qualitative elements. Results of the quantitative analysis are presented first proceeded by qualitative findings. Following the embedded research design (Creswell \& Clark, 2011), a combined summary of quantitative and qualitative results are then presented.

\section{Quantitative}

I hypothesized that following the storytelling event, participants would report significantly more favorable attitudes towards LG older adults. The paired samples $t$-test was used to assess the differences in participants' attitudes on pretests and posttests. 
Prior to analyses, the data was pre-analyzed to test for normality. Box plots in SPSS and the outlier labeling rule (Hoaglin, Iglewize, Tukey, 1986) were used to identify outliers. Four cases, identified as extreme outliers, were removed from the analysis. Following the removal of extreme outliers, histograms were used to further assess the distribution of the differences between pre and posttests. For the two subscales (attitudes toward lesbians and attitudes towards gay men) and the full scale (attitudes toward LG), the distribution of the differences were approximately normally distributed. Each of the histograms revealed positive kurtosis; the stronger center peak is consistent with the greater distribution of difference in the zero range. As $t$-tests are robust to violations of normality, this violation is not anticipated to invalidate results.

In-group members generally hold other in-group members in high regard (Allport, 1979). Because this may influence results, prior to the analysis differences in the pretest attitude scores of participants by sexual orientation was also explored. Participants who identified as sexual minorities were compared to participants who identified as heterosexual. Sexual minority participants $(\mathrm{n}=7, \mathrm{M}=47.57, \mathrm{SD}=3.55)$ reported significantly more positive attitudes toward lesbians on pretests than heterosexual participants $(\mathrm{n}=43, \mathrm{M}=42.21, \mathrm{SD}=6.55), t(48)=3.21, \mathrm{p}=.006, \mathrm{~d}=1.06$. Sexual minority participants $(\mathrm{n}=7, \mathrm{M}=48.00, \mathrm{SD}=3.65)$ reported significantly more positive attitudes toward gay men than heterosexual participants $(\mathrm{n}=42, \mathrm{M}=42.21, \mathrm{SD}=7.24), t(47)=3.51$, $\mathrm{p}=.003, \mathrm{~d}=1.15$. Sexual minority participants $(\mathrm{n}=7, \mathrm{M}=95.57, \mathrm{SD}=7.12)$ reported significantly more positive attitudes toward combined LG on pretests than heterosexual participants $(\mathrm{n}=41, \mathrm{M}=84.10, \mathrm{SD}=12.77), t(46)=3.43, \mathrm{p}=.004, \mathrm{~d}=1.15$. Results for both subscales and the combined scale suggest that sexual orientation had very large effects 
(Cohen, 1992) on attitude scores. To further evaluate the impact of sexual orientation when answering Research Question One, $t$-tests are presented in two ways: With all participants included (Table 4), and with only heterosexual participants (Table 5).

Table 4

Results of t-test and Descriptive Statistics for Attitudes toward LG-all Participants

\begin{tabular}{|c|c|c|c|c|c|c|c|c|c|}
\hline & \multicolumn{3}{|c|}{ Pre } & \multicolumn{3}{|c|}{ Post } & \multirow{2}{*}{$\begin{array}{l}95 \% \text { CI for } \\
\text { Mean } \\
\text { Difference }\end{array}$} & \multirow[b]{2}{*}{$T$} & \multirow[b]{2}{*}{$\mathrm{df}$} \\
\hline & $\mathrm{M}$ & SD & $\mathrm{n}$ & $M$ & SD & $\mathrm{n}$ & & & \\
\hline $\begin{array}{l}\text { Attitudes } \\
\text { toward lesbians }\end{array}$ & 43.24 & 6.21 & 49 & 44.08 & 6.13 & 49 & $.18,1.49$ & $2.56^{*}$ & 48 \\
\hline $\begin{array}{l}\text { Attitudes } \\
\text { toward gay men }\end{array}$ & 42.69 & 7.27 & 48 & 43.83 & 6.56 & 48 & $.25,2.05$ & $2.56^{*}$ & 47 \\
\hline $\begin{array}{l}\text { Attitudes } \\
\text { toward LG }\end{array}$ & 87.02 & 11.96 & 45 & 89.04 & 11.34 & 45 & $0.89,3.16$ & $3.60 * * *$ & 44 \\
\hline
\end{tabular}

When all participants are included, results of the independent $t$-test reveals a statistically significant difference in the scores between pretest and posttest in all three areas. Statistically significant increases in positive attitudes toward lesbians $(t=2.56$, $\mathrm{p}=0.014)$, positive attitudes towards gay men $(t=3.32, \mathrm{p}=.014)$ and positive attitudes towards both $\mathrm{LG}(t=3.60, \mathrm{p}=.001)$. Cohen's $\mathrm{d}$ was used to calculate effect sizes for paired sample $t$ tests. These results suggests that the intervention had moderate effects on participants' attitudes toward lesbians $(\mathrm{d}=.37)$, gay men $(\mathrm{d}=.38)$ and $\mathrm{LG}$ combined $(d=.54)$ when all participants are included in the analysis. 
Table 5

Results of t-test and Descriptive Statistics for Attitudes toward LG-Heterosexual Participants

\begin{tabular}{|c|c|c|c|c|c|c|c|c|c|}
\hline & \multicolumn{3}{|c|}{ Pre } & & Post & & \multirow{2}{*}{$\begin{array}{c}95 \% \text { CI for } \\
\text { Mean } \\
\text { Difference }\end{array}$} & \multirow[b]{2}{*}{$t$} & \multirow[b]{2}{*}{$\mathrm{df}$} \\
\hline & $\mathrm{M}$ & SD & $\mathrm{n}$ & $\mathrm{M}$ & SD & $\mathrm{n}$ & & & \\
\hline $\begin{array}{l}\text { Attitudes toward } \\
\text { lesbians }\end{array}$ & 42.52 & 6.29 & 42 & 43.43 & 6.23 & 42 & $.18,1.63$ & $2.53 *$ & 41 \\
\hline $\begin{array}{l}\text { Attitudes toward } \\
\text { gay men }\end{array}$ & 42.10 & 7.17 & 40 & 43.40 & 6.28 & 40 & $.23,2.38$ & $2.45^{*}$ & 39 \\
\hline $\begin{array}{l}\text { Attitudes toward } \\
\text { LG }\end{array}$ & 85.45 & 12.04 & 38 & 87.66 & 11.54 & 38 & $.92,3.51$ & $3.46^{* * *}$ & 37 \\
\hline
\end{tabular}

When only heterosexual participants are included in the analysis, the results were similar. Statistically significant differences in the scores between pretest and posttest were also noted in all three categories. Significant increases in positive attitudes toward lesbians $(t=2.53, \mathrm{p}=0.015)$, positive attitudes towards gay men $(t=2.45, \mathrm{p}=.019)$ and positive attitudes towards both lesbians and gay men $(t=3.46, \mathrm{p}=.001)$. The results suggests that the moderate effects of the intervention increased on attitudes toward lesbians $(\mathrm{d}=.39)$, gay men $(\mathrm{d}=.40)$, and combined LG $(\mathrm{d}=.57)$ when sexual minority participants are removed from the analysis. In response to the quantitative portion of Research Question One, the results of $t$-tests indicate that after participating in the storytelling event, participants' attitudes were significantly more positive.

\section{Qualitative}

To further explore participants' attitudes towards LG older adults, qualitative data was analyzed. Qualitative data was used to explore two areas: How do participants verbal and written narrative responses compare to quantitative findings related to attitudes towards LG older adults; and to identify emerging themes in participants verbal 
and written narratives not captured in the quantitative data analysis. Prior to data analysis, audio recordings from the group discussions that proceeded the storytelling event were transcribed into a Word document. All written comments on posttest surveys were collected into a single Word document. Field notes were also composed in a Word document. The Word documents were double spaced and formatted with large margins to facilitate manual coding.

An eclectic combination of provisional, versus, in-vivo and emotional coding (Saldana 2013) was applied to qualitative data during the first coding phase. The process resulted in 90 initial codes (see Figure 3) that encompassed a wide range. In round two, process coding was applied. Process coding was selected because it can be beneficial with grounded theory approaches to both explore emerging themes and it is a good mechanism for exploring interactions, perceptions and responses to situations (Saldana, 2013).

The reflective and analytical practice of process coding resulted in 13 process codes. Definitions were developed for each process code. Further qualitative analysis was applied by reflecting on the process codes and utilizing color coding to identify codes with overlapping elements. Thematic analysis of the process codes, initial codes, supporting direct quotations, and data resulted in the identification of five themes. These process codes, definitions, corresponding themes and interpretations are presented in Table 6. 


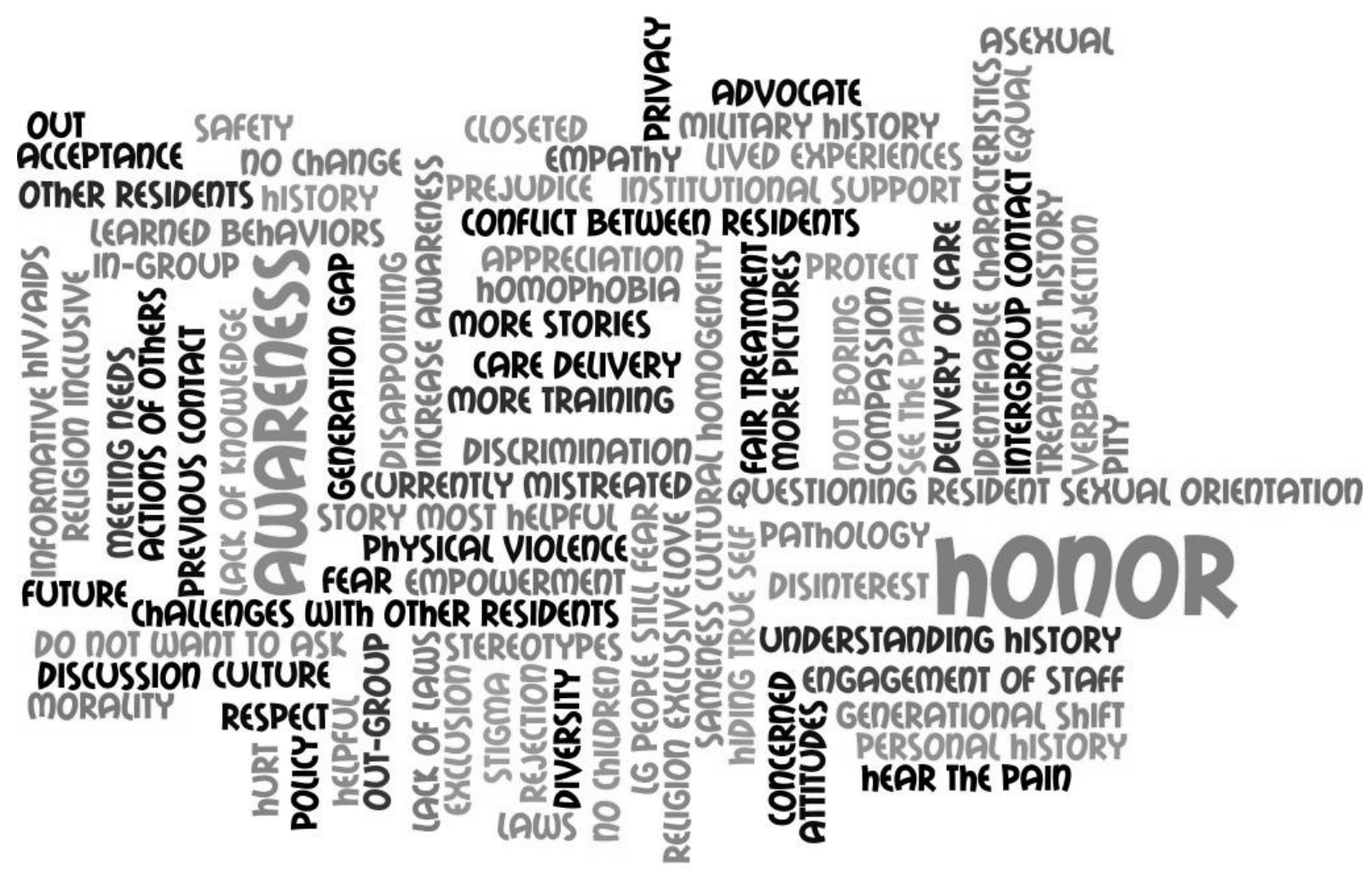

Figure 3. Wordle depiction of the 90 codes that emerged during round one coding

The reflective and analytical practice of process coding resulted in 13 process codes. Definitions were developed for each process code. Further qualitative analysis was applied by reflecting on the process codes and utilizing color coding to identify codes with overlapping elements. Thematic analysis of the process codes, initial codes, supporting direct quotations, and data resulted in the identification of five themes. These process codes, definitions, corresponding themes and interpretations are presented in Table 6.

Research Question 1a. In regards to question 1a, qualitative findings are similar to quantitative findings. Like quantitative findings, qualitative findings suggests that LTC staff's responses to the storytelling event appeared to increase awareness of LG older adults. Of the five themes identified in the analysis, four are relevant to Research 
Question 1a. Each of these themes are reviewed with supporting quotations from participants.

Making meaning of the stories. The theme of, making meaning of the stories, illustrates how staff increased their awareness of LG older adults by connecting information from the storytelling event to societal laws and agency policy. Participants described their reactions to the stories and the meanings that emerged. During a group discussion that followed the storytelling event, a male participant described what it must be like for an LG older adult entering LTC: "I can imagine that it can be uncomfortable to go into a facility not knowing how the staff and everything is going to be." During a group discussion this female participant discusses how the stories helped her to understand how LG older adults may experience discrimination. "You know, we thought we were way past that, but we're not, that generation carries a lot." This female participant shares how the storytelling event helped her to realize why LG older adults may hide their sexual orientation considering the power differential in the relationship between caregiver and resident. "So, I like get why people would not want to share that information. I mean they are in an environment where they are dependent on someone else to give them the care that they need." This female participant goes on to explain how she might handle working with an LG older adult. "I think it [storytelling] changes my perspective on how, if I did think somebody was lesbian or gay and they disclosed that information to me, I would be very protective of that to help protect the person."

Seeking more information and understanding. Additionally, participants expressed a desire to understand the context of stories as reflected in the theme of seeking more information and understanding. Participants' efforts to further understand the 
personal experiences of the storytellers were evidenced in the questions asked and other comments. One participant appeared to be surprised that the video was made with people who are still alive today and that the interviews for the video were completed in March of 2015. "How old is this [storytelling video]? This participant wanted to know how family relationships worked out for the female in the story. "Did she [storyteller] have a relationship with her kids again?" A male participant wanted to know if the experiences of the storytellers were exceptional or the norm: “... and those stories are probably very typical, probably the typical story?" The question prompted the facilitator to explain that both of the people in the video were new to him when the interviews were conducted and that these were random individuals who were referred as potential candidates to share their life histories for this study. Neither of the storytellers considered their stories exceptional when they talked about their experiences in comparison to their peers. 


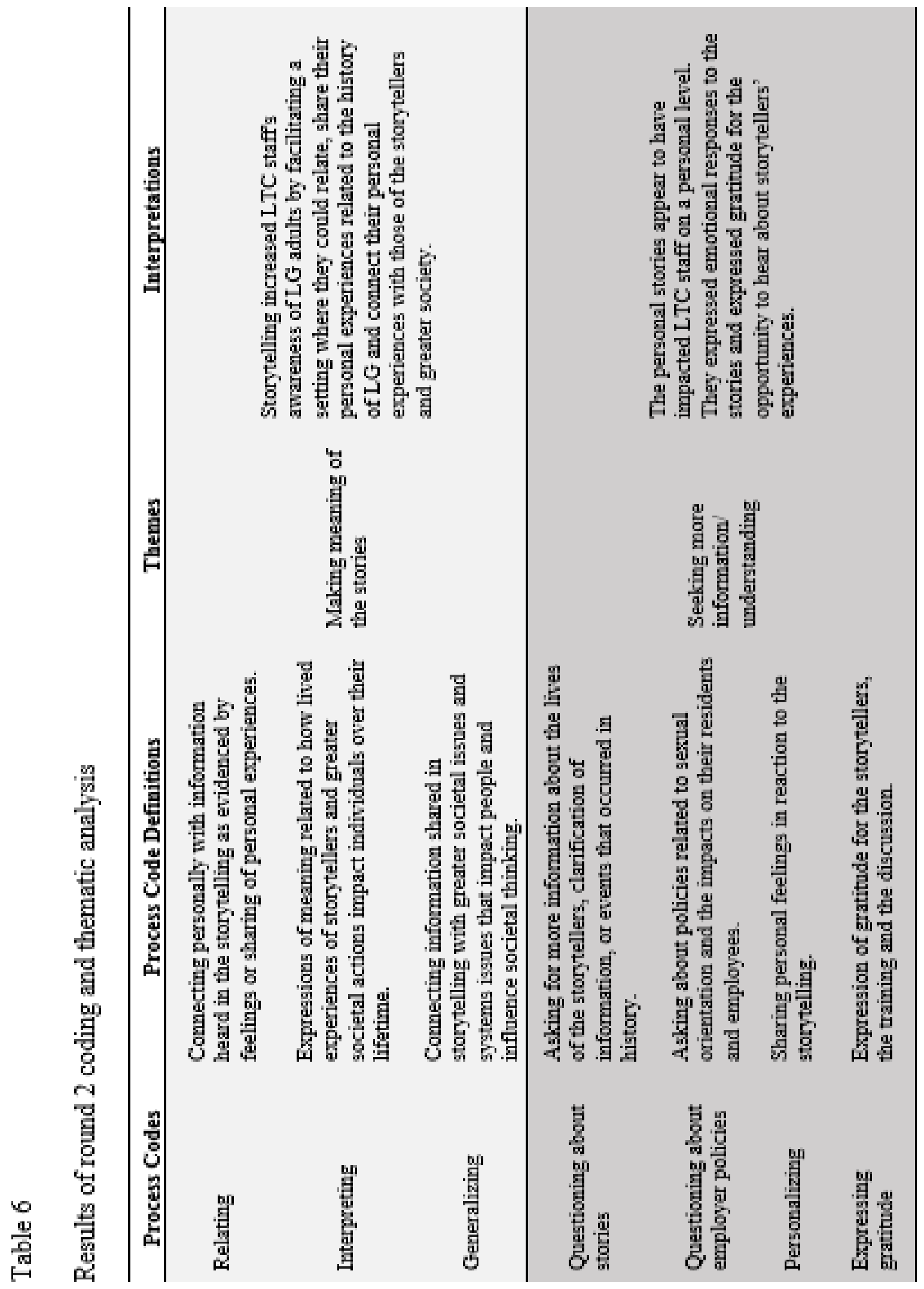




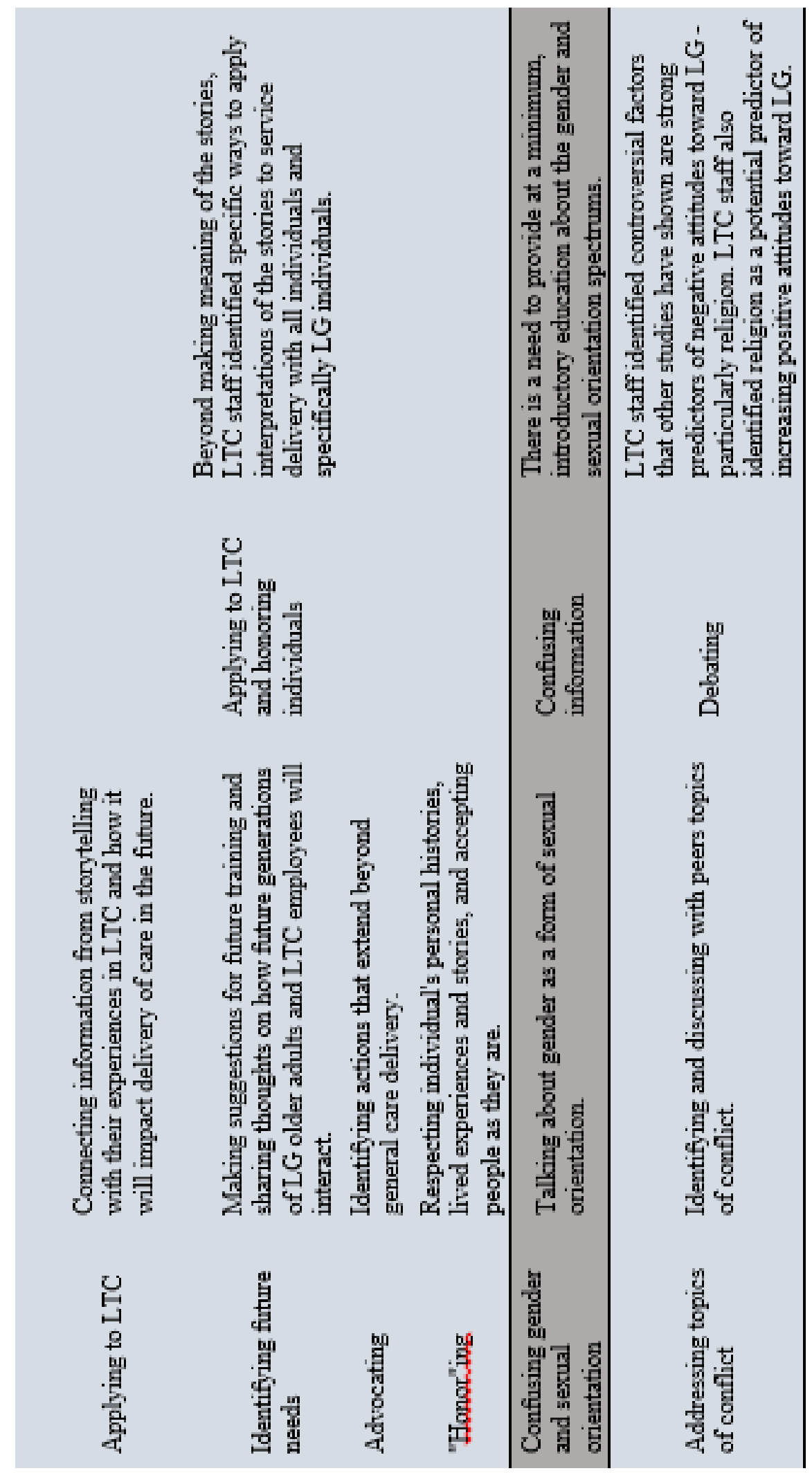


Application of LTC and honoring individuals. Data analysis resulted in a theme of application to LTC and honoring individuals. Participants' described ways that they may personally apply the information or how their organization can be inclusive of and respectful of LG older adults in care delivery. Participants described several areas where information increased their awareness related to LTC service delivery. Participants identified how older LG adults may withhold information. This female participant surmised that LG older adults are not likely to disclose their sexual orientation even when it may have meaning for care: "They are not telling us..." In response, another female participant pointed out how the topic of sexual orientation is not discussed with residents: “...and we are not asking them." On posttest surveys, participants described how information from the storytelling event and the discussion that followed will impact how they do their jobs in LTC settings. "The fear that Donna and Orval [storytellers] expressed will affect my sensitivity to G \& L older adults." "I will be more attentive to the needs that are caused by the fear of being judged."

Debating. Finally, participants had passionate conversations about controversial matters as identified in the theme of debating. Participants expressed concerns about conflicting values among LTC employees and other residents related to serving LG older adults. Their remarks reflect the dual views on religion as it relates to attitudes toward sexual orientation. In response to a participant's comment about how difficult it is to change behavior, a female participant expresses her views related to the role of religion. "One thing I do not think you're ever going to get away from that was the religious side of things... it will always be there..." Another participant identifies specific religions that have a history of negative views toward sexual minorities. "Because you may be dealing 
with a Muslim that doesn't believe in it [LG] or you may be dealing with a strong Catholic or whatever." Participants offered opposing views by expressing ways in which religion can be inclusive of sexual minorities. "Which is really sad because religion is supposed to teach you to love." "It's just how they choose to do the interpretation." In regards to religion, one participant identified a homogenous environment where both staff and residents are rarely exposed to other religious views and interpretations. She described the setting as "here [in this community] it is our way or no way." In this passionate conversation, the same participant offered a suggestion. "You get to know somebody else's beliefs; they don't have to be your beliefs." One participant had a highly emotional reaction to the conversation and approached the facilitator after the event to discuss her religious beliefs and approach to delivering care.

Because I am... I am a very strong Christian I believe $100 \%$ of the Bible. Just because I view it [LG] as a sin and I see it as wrong doesn't give me any right to treat people differently at all because I don't...

Similarly, debating themed conversations occurred in regards to serving LG older adults and other older adults who are homophobic in the same facility or the same resident room. A participant's comments suggests that homophobia among residents may be a greater issue than homophobia among staff. "They [other residents] are more judgmental than our staff are now... we are here to take care of our residents." Comments such as this one relay the degree of concern from some of the LTC staff. "We have a gentleman here that if he found out his roommate was homosexual he would beat the crap out of him, in a heartbeat." Others offered suggestions on how to address the 
issues. "You just have to monitor the environment and help with the generational gap, it disappears over time." "You have to consider rooms, we have semi-private rooms... so you have two males that are sharing a room or two females that are sharing a room and they have two different backgrounds."

Results qualitatively illustrate how LTC staff appeared to have increases in awareness of LG older adults. LTC care staff identified ways that their awareness of LG older adults applies to the delivery of LTC services. There were also themes and codes that stood out as emerging. Those areas are reviewed next in respect to Research Question 1b.

Research Question 1b. This research question was included in this study to further assess the influence of storytelling on attitudes towards LG and capture data that may not be captured otherwise. In regards to Research Question 1b, patterns in the qualitative data emerged that suggest new or expanded areas of consideration. There areas surfaced; each is explored.

Honor. The code of honoring residents emerged. Although honor is also encompassed in one of the themes, the connotation of the term honor in the data implied a meaning that surpassed respect. Participants' contextual use of the term honor implied reverence, acceptance, and appreciation for persons that included an element of protection. The intensity is demonstrated in this quote: "At another facility I worked at there was a gentleman that went out every night to visit a [gay] friend and staff just recognized it, and you just honor it. That's their business and it felt protective." This intense meaning that appears to stem from personal experiences and learning about the experiences of others warrants further exploration. The elements of safety and protection 
that were apparent in the concept of honor also emerged as a separate area that warrants further exploration.

Safety and protection. Codes that emerged from this qualitative data analysis related to safety and protection were particularly focused on a perceived need of LTC staff to potentially protect LG residents from other residents that may have deeply engrained homophobia. On as posttest survey, a participant described how this concept may manifest in LTC: "I will do my very best to create a safe environment but I'm saddened that I'm limited in the control of actions of others."

Confusing sexual orientation and gender. Participants at each site appeared to confuse information related to the concepts of sexual orientation and gender identity and expression during the group discussions. For example, when referring to working with gay people a staff person stated, "We were one of the first hospitals to do transgender surgeries...seeing those patients come in very confused..." Her response implied that sexual orientation and gender identity or expression are synonymous.

Confusing information, honor, and safety and protection are areas that emerged from this analysis that are new areas to explore related to research and training.

Research Question 1 summary: Research Question One served as the primary research question for this study. The quantitative results revealed that storytelling had a significant and positive influence on participants' attitudes toward LG older adults. These findings were further substantiated by qualitative findings. Themes suggested that participants connected with storytellers and made meaning of the information as it related to them both personally and professionally in LTC settings. Furthermore, participants shared information that lead to the identification of areas that warrant further training, 
discussion and research. This is discussed in more detail in Chapter Five. Next, differences in attitudes toward LG related to gender of participants is explored.

\section{Research Question \#2}

Research Question Two was: How does storytelling influence male and female respondent's attitudes towards LG differently? I hypothesized that following the storytelling event, female participants would report significantly more favorable attitudes towards LG older adults than male participants. An independent samples $t$-test was completed to compare the differences in pretest-posttest attitude scores between female and male participants.

As detailed in Table 7, changes in mean attitude scores for female participants were higher in both subscales and the combined scale when compared to male participants. However, there was not a statistically significant difference in the scores between females $(\mathrm{M}=0.90, \mathrm{SD}=2.35)$ and male $(\mathrm{M}=0.55, \mathrm{SD}=2.07)$ participants' attitudes

towards lesbians, $t(47)=.41, \mathrm{p}=0.69$. There was not a statistically significant difference in the scores between female ( $M=1.17, \mathrm{SD} 3.22)$ and male $(\mathrm{M}=1.00, \mathrm{SD}=2.65)$ participants' attitudes toward gay men, $t(46)=0.16, p=0.88$. Finally, there was not a statistically significant difference in the scores between female (M=2.14, SD 3.89) and male $(\mathrm{M}=1.56, \mathrm{SD}=3.40)$ participants' attitudes toward LG combined $t(43)=0.41, \mathrm{p}=0.68$. Results suggest that even though the storytelling event influenced female and male participants differently, the difference was not statistically significant. Next the relationship between religiosity and attitudes toward LG is analyzed. 
Table 7

Results of t-test and Descriptive Statistics for Difference in Pre and Post Test Attitude Scores

\begin{tabular}{|c|c|c|c|c|c|c|c|c|c|}
\hline & \multicolumn{3}{|c|}{ Female } & \multicolumn{3}{|c|}{ Male } & \multirow{2}{*}{$\begin{array}{l}95 \% \text { CI for } \\
\text { Mean } \\
\text { Difference }\end{array}$} & \multirow[b]{2}{*}{$T$} & \multirow[b]{2}{*}{$\mathrm{df}$} \\
\hline & $\mathrm{M}$ & SD & $\mathrm{n}$ & $\mathrm{M}$ & SD & $\mathrm{n}$ & & & \\
\hline $\begin{array}{l}\text { Difference in } \\
\text { Attitudes toward } \\
\text { Lesbians }\end{array}$ & 0.90 & 2.35 & 40 & 0.55 & 2.07 & 9 & $-1.37,2.06$ & 0.41 & 47 \\
\hline $\begin{array}{l}\text { Difference in } \\
\text { Attitudes toward Gay } \\
\text { Men }\end{array}$ & 1.17 & 3.22 & 39 & 1.00 & 2.65 & 9 & $-2.15,2.51$ & 0.16 & 46 \\
\hline $\begin{array}{l}\text { Difference in } \\
\text { Attitudes toward } \\
\text { Lesbians \& Gay men }\end{array}$ & 2.14 & 3.89 & 36 & 1.56 & 3.40 & 9 & $-2.28 ., 3.44$ & 0.41 & 43 \\
\hline
\end{tabular}

\section{Research Question 3}

Research Question Three examined the relationship between religiosity and attitudes towards LG older adults among LTC providers who participated in this study. I hypothesized that when controlling for previous acquaintance with an LG person and age, increases in religiosity are associated with more negative attitudes towards LG older adults. Prior to completing the multiple regression, bivariate correlation was performed to identify possible multicollinearity between the predictor variable and control variables, and to explore correlations between the predictor and control variables with outcome variables (Table 8). 
Table 8

Bivariate Correlations

\begin{tabular}{lccc}
\hline Variables & 1 & 2 & 3 \\
\hline Predictor & & & \\
$\quad$ 1. Religiosity & - & & \\
Controls & & & \\
2. Previous acquaintance & 0.134 & - & - \\
3. Age & 0.221 & $.247^{*}$ & \\
Outcome & & & -231 \\
$\quad$ Attitudes toward LG & $-0.292^{*}$ & $-0.277^{*}$ & -.231 \\
\hline$* p<.05$. one-tailed & & &
\end{tabular}

Multicollinearity was not problematic as there were no correlations above .6 between the predictor variable and the control variables. There was, however, a statistically significant and small, positive correlation between the two control variables, age and previous acquaintance with $L G, r=.247, p=.040$. Multicollinearity was further assessed by examining the variance inflation factor (VIF) and tolerance values.

Table 9

Summary of Regression Analyses for Religiosity Predicting Attitudes Toward LG when Controlling for Age and Previous Acquaintance

\begin{tabular}{|c|c|c|c|c|c|c|c|c|c|c|}
\hline & & & $\begin{array}{c}\text { Model } \\
1\end{array}$ & & & & & $\begin{array}{c}\text { Model } \\
2\end{array}$ & & \\
\hline Variable & $B$ & $S E B$ & $\beta$ & $t$ & $p$ & $\beta$ & $\begin{array}{c}S E \\
B\end{array}$ & $B$ & $t$ & $p$ \\
\hline Religiosity & -3.54 & -3.96 & -0.24 & -1.73 & .091 & -3.96 & 2.03 & -0.26 & -1.94 & .058 \\
\hline $\begin{array}{l}\text { Previous } \\
\text { acquaintance }\end{array}$ & -13.53 & 8.32 & -0.23 & -1.63 & .110 & -14.83 & 8.16 & -0.24 & -1.82 & .075 \\
\hline Age & -0.14 & 0.15 & -0.13 & -0.92 & .363 & & & & & \\
\hline $\mathrm{N}$ & & & 51 & & & & & 52 & & \\
\hline$R^{2}$ & & & 0.16 & & & & & 0.14 & & \\
\hline$F$ & & & $3.06^{*}$ & & & & & $4.09^{*}$ & & \\
\hline
\end{tabular}

Model 1, $n=51$, Model 2, $n=52 ; * p<.05$. 
Model 1 regression analysis reveals that VIF values ranged from a low of 1.02 to a high of 1.10. Tolerance values ranged from .91 to .98. VIF and tolerance values further suggest that multicollinearity was a not a problem. The Durbin-Watson value of 1.28 indicates the assumption of independence of errors is defendable. The scatterplot of standardized predicted values revealed some variation from normality suggesting the possibility of heteroscedasticity. Because the control variable of age was positively skewed, attempts were made to improve the normality of the residuals by transforming the age variable. However, neither log nor quadratic transformations improved the skewness for this variable. A possible threat of heteroscedasticity is present in this analysis. This may serve as an indicator that other significant predictors of attitudes toward LG are not included in this multiple regression.

In the overall model (Table 9, Model 1) the predictor variable (religiosity) and both control variables (age, corresponding previous acquaintance factor) are included. The size and the direction of the relationship between religiosity and attitudes toward LG $(B=3.54)$ indicates that as participants level of religiosity decreased by 3.54 units, their attitudes toward LG increased by one unit when controlling for previous acquaintance and age. In regards to predicting attitudes toward LG, the overall model was statistically significant, $\mathrm{R}^{2}=.164, \mathrm{R}^{2}$ adj $=.11, \mathrm{~F}(3,47)=3.064, \mathrm{p}=.037$. The predictor variable and both control variables had negative influences on attitudes towards LG. Religiosity had the strongest influence on attitudes towards LG $(\beta=-.24)$ followed by the control variables of previous acquaintance $(\beta=-.23)$ and age $(\beta=-.13)$. However, in Model 1, neither religiosity $(p=.09)$ nor the control variables of previous acquaintance with an LG 
person $(\mathrm{p}=.11)$ or age $(\mathrm{p}=.36)$ were statistically significant predictors. Variables included in this model accounted for $16 \%$ of the variance in attitudes toward LG.

Age was included in Model 1 because age was included as a control variable in the original hypothesis for Research Question Three in this study. However, because age was not significantly correlated with the outcome variables and was not a statistically significant predictor in model 1 , the regression was run again with age removed (Table 9, Model 2). When age was removed, results indicate that when controlling for previous acquaintance, a decrease of 3.96 units of religiosity is associated with a one unit increase in scores of attitudes toward LG. Like model 1, model 2 was statistically significant for predicting attitudes toward gay men, $\mathrm{R}^{2}=.14, \mathrm{R}^{2}$ adj $=.11, \mathrm{~F}(2,49)=4.09, \mathrm{p}=.023$. Though not statistically significant, religiosity $(\mathrm{p}=.058)$ and previous acquaintance $(p=.075)$, appear to have clinical significance. The predictor variable and the control variable included in this model accounted for $14 \%$ of the variance in attitudes toward gay men.

I hypothesized that when controlling for previous acquaintance with an LG person and age, increases in religiosity are associated with more negative attitudes towards LG older adults. Results suggest that in this model, religiosity was not a statistically significant predictor of attitudes toward LG.

\section{Summary of Results}

This chapter provided a description of the results of the statistical analysis for this study. Quantitative and qualitative findings used to answer Research Question One suggest that the storytelling intervention had a positive influence on LTC staff members' attitudes toward LG older adults. Research Question Two looked at differences in 
attitude scores by gender. There were differences in male and female participants' attitudes towards LG, however, the differences were not statistically significant. Research Question Three looked at the relationship between religiosity and attitudes towards LG. Results of regression analysis revealed that although religion was negatively correlated with attitudes towards LG, it was not a scientifically statistically significant predictor in this study; however, results may have clinical significance. Discussion of these findings and implications for social work are discussed in Chapter Five. 


\section{CHAPTER FIVE: DISCUSSION}

In this chapter, first a summary of the purpose and an overview of this intervention study are provided. Next, a discussion of the findings and the significance of findings for each research question as results relate to the scholarly literature is reviewed. Implications for further research and practice are presented followed by concluding remarks.

\section{Overview and Summary}

With the growing population of older adults, more people are seeking long-term care (LTC). Among the diverse population of older adults are millions of LG adults that are projected to need LTC at rates higher than the general population. However, due to societal stigmatization and fears of discrimination, older LG adults are less likely to seek LTC services leaving them at risk for going unserved and having LTC needs that are not met. Increasing the awareness of sexual minorities among LTC providers is identified as a first step to address this problem (Morales, et al., 2014).

The purpose of this study was to explore how intergroup contact (IGC) through a storytelling intervention influences LTC staff members' awareness and attitudes toward LG older adults. Three research questions explored (1) how storytelling influences LTC staff members' attitudes towards LG older adults measured quantitatively and qualitatively; (2) how storytelling influenced male and female participant's attitudes toward LG differently; and (3) explored the relationship between religiosity and participants attitudes towards LG. To answer these questions, this study employed a mixed methods, embedded design. Guided by IGC theory, quantitative methods were used as the primary approach with an embedded qualitative element informed by 
grounded theory. IGC theory has been studied for more than 60 years and has been shown to increase favorable attitudes towards marginalized groups. The qualitative element aided in understanding quantitative findings and created the opportunity to identify emerging themes that would not be identified in the quantitative analysis.

To carry out this study, the stories of an older lesbian and an older gay man were collected during videotaped interviews. The interviews were edited to create the storytelling intervention. The storytelling intervention was then tested at LTC care sites in central Missouri. Study participants were made up of LTC employees who completed the pretest measure of attitudes toward LG; participated in the storytelling intervention that included viewing the storytelling video and an audio-recorded group discussion; and completed the posttest measure of attitudes towards LG and answered open-ended questions in writing. Quantitative data for this study was analyzed using SPSS. Qualitative data was analyzed manually using a variety of coding methods to identify codes, define codes, identify theme and interpret themes. Next, the findings from the data analysis are discussed.

\section{Discussion of the Findings}

This study aimed to reach particular LTC care staff; therefore findings from the analysis of the descriptive data of the participants are discussed first. Then, a discussion of the findings for each research question are presented.

\section{Descriptive Data}

This study was designed with the aim to include LTC staff members' who were representative of the providers in the geographical area where the study was conducted. The study also intended to include LTC staff members' who have significant amounts of 
contact with LTC residents. Not surprisingly, more than three quarters of this sample was female. Results are consistent with other studies conducted with this population that found that females represented the largest portion of staff members who work in LTC settings (Leyva et al., 2013; Hinrichs \& Vacha-Haase, 2010; Porter \& Krinsky, 2014). The majority of the sample also self-identified as white or Caucasian, which is reflective of the geographical area of counties in central Missouri where data was collected (U.S. Census Bureau, 2015). It can be concluded that this sample is likely representative of the gender make up of a LTC facility and the racial and ethnic makeup of participants is representative of the geographical area where data was collected.

This study aimed to reach certified nursing assistants (CNA) and other staff members who provide the most direct service to LTC residents in other capacities. It is important to explore CNA's attitudes toward LG because they provide the bulk of the direct care to LTC residents (Schrim, 2000). Almost half of the participants in this study were CNA's, and nearly $40 \%$ of the remainder worked as nurses or provided direct care to LTC residents in another capacity (e.g.; physical therapy, social services). It can be concluded that this study met the aim of reaching the LTC staff who provide direct care. Next, findings related to Research Question One are discussed.

\section{Research Question One}

In Research Question One, how storytelling influenced LTC staff members' attitudes towards LG older adults was assessed quantitatively and qualitatively. Quantitatively, staff members' attitudes at posttest were significantly higher than at pretest. It can be concluded that the storytelling intervention had a positive impact on LTC staff members' attitudes towards LG. Quantitative findings were also supported 
with qualitative findings that revealed that staff members connected intellectually and emotionally with the information presented in the stories. The positive findings are not surprising considering the extensive application of IGC and findings of previous studies that tested IGC theory (Pettigrew \& Tropp, 2011). However, the moderate effects of the storytelling intervention on participants' attitudes toward LG found in this study are surprising when taking into consideration the indirect modality of the contact. In this study, IGC contact between in-group members (i.e., LTC staff members) and outgroup members (i.e., LG older adults) took place via the storytelling event in the form of the pre-recorded video. Allport (1954) posited that IGC via indirect methods would be effective with increasing positive relations between groups. He also identified this as an area where additional research was needed. Allport suggested that indirect contact may be the preferred method to introduce some groups of people. Results of this study support Allport's hypothesis related to indirect contact made more than half a century ago.

It can also be speculated that the results derived from Research Question One support Allport's hypothesis related to the importance of including elements of the human experience in the nature of the contact. Allport (1954) posited that when the content of the contact includes elements that convey the human experience as a member of the out-group, it is more likely to produce positive effects. In other words, content that communicates how stigmatization and discrimination negatively impacts an individual person (i.e., a patient, a resident, an older adult) is more likely to have positive influences on participants' attitudes. In this study, storytellers shared their personal experiences related to areas such as discrimination at work and exclusion from family as a result of 
identifying as a sexual minority. Study participants appeared to relate to their experiences which in turn appeared to positively influence their attitudes towards LG older adults. These findings were revealed in qualitative findings.

Qualitative analysis produced process codes that suggested specific ways that LTC staff members connected intellectually (e.g., interpreting, generalizing, advocating) and emotionally (e.g., relating, personalizing, honoring) with information from the storytelling intervention. As evidenced by the qualitative results of this study, IGC delivered by indirect storytelling can help participants to conceptualize how what is happening in the world connects to the individual person (Alterio, 2003). Viewing the lived experiences of others via the video storytelling event appeared to influence the participants by shifting their thinking about the lived experiences of LG older adults. Participants described how the treatment by others impacted the storyteller's lives and they appeared to interpret that by applying the meanings to their work in the delivery of LTC services. Participants described how their actions may impact the people they serve, and how the power that they possess as an employee in a LTC setting, may impact LG older adults.

\section{Research Question Two}

Research Question Two explored how storytelling impacted male and female participants differently. Previous research has shown that men often hold more negative attitudes toward sexual minorities, and that IGC related to attitudes toward sexual minorities, has a smaller effect on men (Herek \& McLemore, 2013). Other studies have shown no significant differences in women and men's attitudes (Bernstein, 2012; Heinze, 2009) suggesting that gender as a predictor of attitudes is inconclusive and warranted 
further investigation. In this study, although female participants' attitudes toward LG scores increased more than male participants' attitudes towards LG, the differences were not statistically significant. Taking into consideration the small sample size and the small number of male respondents in this study, it can be concluded that the influence of storytelling on attitudes toward LG older adults by gender of participants are inconclusive.

\section{Research Question Three}

In Research Question Three, the relationship between religiosity and attitudes toward LG older adults was explored by conducting a multiple regression analysis. Results revealed that religiosity was not a scientifically significant predictor of participants' attitudes towards LG in the relatively small sample of LTC staff that participated in this study. However, regression results did suggest clinical significance. Including religiosity as a variable in studies that explore attitudes towards LG is warranted. Though Research Question Three did not have a qualitative element, results of the qualitative analysis used to answer Research Question One are related to the findings of the multiple regression analysis in Research Question Three. LTC staff that participated in this study qualitatively described religion as both a potential predictor of negative attitudes and a potential predictor of positive attitudes toward LG. Qualitatively, participants in this study identified how religion can be interpreted to both include all people equally and exclude certain groups of people. It can be concluded that the relationship between religiosity and attitudes towards LG in this study was inconclusive and warrants further exploration. Next, implications for social work that stemmed from this study are presented. 


\section{Implications for Social Work}

The results of this research further support Carter-Black's (2007) call to action for social workers to employ storytelling. Results of this small study revealed that storytelling had a positive influence on LTC staff members' attitudes towards LG in central Missouri. As the profession that provides the largest proportion of social services in the United States and the arm of the social sciences committed to serving the most vulnerable (NASW, 2008), social work is well-positioned to use storytelling. The nature of the work and the mission of the profession facilitates the opportunity to capture the stories of individuals that we serve and use them in a way that respects the individual and at the same time communicates the human element to social workers and staff members of other professions.

This study looked at the attitudes of LTC care providers as they relate to LG older adults. There are other groups on the spectrum of sexual orientation such as bisexuality. Because people have differing attitudes towards different sexual orientations, additional work is warranted that explores attitudes of providers toward different groups on the spectrum of sexual orientation. Related to this matter, results of this study also revealed the importance of providing participants with basic information related to sexual orientation, gender identity and gender expression. In training and research projects, introductory information should, at a minimum, provide participants with the definition of these terms, provide an overview of how each is different, and emphasize how the meanings are not synonymous.

Beyond exploring staff attitudes toward LG, future work is needed to explore how attitudes and beliefs towards LG among residents may impact the delivery of care 
services and quality of life. LTC staff who participated in this study identified concerns around the safety of LG residents who may reside in LTC settings where they may encounter fellow residents who hold strong homophobic beliefs. Specifically, LTC staff identified the need for providers and researchers to explore ways to serve all residents that would include protecting and honoring LG residents while also honoring the values of other residents.

Even though results of this study are inconclusive as to the relationships between gender of research participants and attitudes towards LG, there are factors related to gender that warrant further exploration. In this analysis, differences in attitudes toward lesbians compared to gay men by gender of participant were not analyzed. However, on both pretest and posttest measures, attitudes towards lesbians were more positive than attitudes towards gay men. Additional research may further explore how LTC providers regard lesbians and gay men differently and explore the development of training materials that take the differences into consideration.

Future research may more deeply explore the various ways in which religiosity is associated with attitudes towards LG. In studies of IGC, religiosity has been identified as the strongest predictor of negative attitudes towards LG (Herek \& McLemore 2013). Historically, Allport (1954) identified religiosity as the basis for most prejudice in society. In this study, with a small sample of volunteer participants, religiosity was not a scientifically significant predictor. However, considering that negative attitudes that are based in a religious moral stance are difficult to change, religiosity is likely to remain a predictor of negative attitudes towards LG (Herek \& McLemore, 2013). Conversely, results of this study suggest that negative attitudes among highly religious participants 
should not be assumed. Like a small study conducted with adolescents (Heinze, 2009), participants in this current study identified religion as a possible predictor of positive attitudes toward LG. Additional work in this area can aid in understanding these opposing views [two extremes] related to religiosity and attitudes towards sexual minorities.

Finally, longitudinal work in this area is needed. Allport (1954) described how IGC works by influencing people on three levels. IGC influences changes in attitudes by effecting how people in the in-group think about the out-group, feel about the out-group, and behave toward the out-group. Results of this study identified how IGC impacted participants thinking towards LG adults and captured how IGC impacts participants' feelings related to understanding the experiences of LG older adults and feelings about serving LG older adults. This study did not, however, assess how IGC influenced participants' behaviors towards LG older adults. Additional research is needed to assess how IGC impacts participants' behavior. This will require that work is longitudinal in nature with points of measure that extend beyond the immediate post-intervention measure, and methods employed to capture data that measures changes in behavior. Longitudinal studies will also provide the opportunity to measure the effects of IGC on thinking and feeling over time.

\section{Study Limitations}

Efforts were made in the design and implementation of this study to reduce the potential for bias and threats to validity. However, this study has several limitations to take into consideration when interpreting the findings. 
Studies that enlist volunteer participants are at risk of selection bias. This is of particular concern in studies that employ IGC approaches to assess attitudes towards sexual minorities as individuals who hold the most negative attitudes are less likely to participate (Dickey, 2013; Hodson, 2011; Pettigrew, 1998).

Survey studies are also subject to threats of social desirability bias. The mixed method design aided in addressing the threat of social desirability bias. Collecting, analyzing and comparing results of both quantitative and qualitative data allowed for testing of hypothesis based in theory and contrasting and verifying quantitative findings with qualitative findings. Additionally, qualitative analysis provided the opportunity to gain a narrative description about attitudes towards LG older adults from LTC staff members' perspectives. There are also limitations associated with using mixed methods approaches, including a relatively small sample, which impacts the rigor of the quantitative analysis.

Though not problematic when analyzing data to answer Research Questions One and Two, the small sample size limited the regression analysis used to answer Research Question Three. This study met the target sample size of 60 participants. The sample size of 60 participants exceeded the minimum of 55 identified in the power analysis computed during the development of this study. However, the number of participants who did not answer all twenty questions on both the pretest and posttest measures of attitudes toward LG limited the total number of responses that could be used for regression analysis. Sample size factors also limit generalizability.

Due to the relatively small sample size and limited geographical area where data was collected, results cannot be generalized. However, the sample in this study is 
reflective of the of the staff make-up of LTC facilities in central Missouri, the model is well grounded in theory, and variables were operationalized and measured in a reliable manner; indicators that results of this study have merit.

\section{Conclusions}

This study set out to explore how storytelling influences LTC staff members' attitudes towards LG older adults. Results revealed that when informed by theory, storytelling is a valuable training modality. This study begins to answer the call for efforts that incorporates storytelling into training. Further, although there exists vast amounts of literature on the use of IGC theory, there is no literature on the use of IGC theory as a guide to increase the awareness of LG older adults in LTC settings. This study serves as a response to the IOM (2011) report that identified a need for interventions that increase the awareness of LG older adults among LTC providers. And finally, this study begins to fill gaps in the literature related to the identified need to develop interventions that are based in theory.

In conclusion, results of this study suggest that storytelling as an intervention for increasing awareness of older LG adults among LTC staff members is an effective training strategy. The model used in this study is shown to positively influence the attitudes of LTC providers towards LG older adults. Based strongly in theory, this model is practical. It can and should be combined with other components to create a more thorough staff training module. This model can be replicated relatively easily in other geographical areas, can be replicated within other service provision areas, and can be replicated to increase awareness of other stigmatized groups. 


\section{REFERENCES}

Allport, G. W. (1935). Attitudes: A handbook of social psychology (pp. 798-844). Worcester, MA: Clark University Press.

Allport, G. W. (1954). The nature of prejudice. Oxford, England: Addison-Wesley. Allport, G. W. (1979). The nature of prejudice. Reading, MA: Addison-Wesley . Alterio, M. (2003). Using storytelling to enhance student learning. York, United Kingdom: The Higher Education Academy.

Bell, S. A., Bern-Klug, M., Kramer, K. W. O., \& Saunders, J. B. (2010). Most nursing home social service directors lack training in working with lesbian, gay, and bisexual residents. Social Work in Health Care, 49(9), 814-831. doi:

$10.1080 / 00981389.2010 .494561$

Bernstein, M., \& Swartwout, P. (2012). Gay officers in their midst: Heterosexual police employees' anticipation of the consequences for coworkers who come out. Journal of Homosexuality, 59(8), 1145-1166. doi:

$10.1080 / 00918369.2012 .673945$

Brener, L., Wilson, H., Rose, G., Mackenzie, A., \& De Wit, J. (2013). Challenging stereotypes and changing attitudes: Improving quality of care for people with hepatitis $\mathrm{C}$ through positive speakers programs. Psychology, Health \& Medicine, 18(2), 242-249. doi: 10.1080/13548506.2012.701753

Brennan-Ing, M., Seidel, L., Larson, B., \& Karpiak, S. E. (2013). Social care networks and older lgbt adults: Challenges for the future. Journal of Homosexuality, 61(1), 21-52. doi: 10.1080/00918369.2013.835235 
Brophy, I. N. (1945). The luxury of anti-negro prejudice. The Public Opinion Quarterly, 9(4), 456-466. doi: 10.2307/2745560

Brotman, S., Ryan, B., \& Cormier, R. (2003). The health and social service needs of gay and lesbian elders and their families in Canada. The Gerontologist, 43(2), 192202. doi: $10.1093 /$ geront/43.2.192

Carter-Black, J. (2007). Teaching cultural competence: An innovative strategy grounded in the universality of storytelling as depicted in african and African American storytelling traditions. Journal of Social Work Education, 43(1), 31-50. doi: 10.5175/JSWE.2007.200400471

Cohen, J. (1988). Statistical power analysis for the behavioral sciences (2nd ed., pp. 567). Hillsdale, NJ: L. Erlbaum Associates.

Cohen, J. (1992). A power primer. Psychological Bulletin, 112(1), 155-159. doi: $10.1037 / 0033-2909.112 .1 .155$

Costa, A. B., Bandeira, D. R., \& Nardi, H. C. (2013). Systematic review of instruments measuring homophobia and related constructs. Journal of Applied Social Psychology, 43(6), 1324-1332. doi: 10.1111/jasp.12140

Creswell, J. W., \& Clark, V. L. P. (2011). Designing and conducting mixed methods research (2nd ed.). Thousand Oaks, CA: Sage.

Crisp, C. (2006). The gay affirmative practice scale (gap): A new measure for assessing cultural competence with gay and lesbian clients. Social Work, 51(2), 115-126.

Darity, W. A. (2007). International encyclopedia of the social sciences.

Davidhizar, R., \& Lonser, G. (2003). Storytelling as a teaching technique. Nurse Educator, 28(5), 217-221. 
De Leeuw, E., \& Hox, J. (2008). Mixing data collection methods: Lessons from social survey In M. M. Bergman (Ed.), Advances in mixed methods research : Theories and applications (pp. 138-149). Los Angeles, CA: SAGE.

Dessel, A., Rogge, M. E., \& Garlington, S. B. (2006). Using intergroup dialogue to promote social justice and change. Social Work, 51(4), 303-315. doi: $10.1093 / \mathrm{sw} / 51.4 .303$

Deutsch, M., \& Collins, M. E. (1951). Interracial housing: A psychological evaluation of a social experiment: Minneapolis, MN: U of Minnesota Press.

Dickey, G. (2013). Survey of homophobia: Views on sexual orientation from certified nurse assistants who work in long-term care. Research on Aging, 35(5), 563-570. doi: $10.1177 / 0164027512447823$

Dixon, J., Durrheim, K., \& Tredoux, C. (2005). Beyond the optimal contact strategy: A reality check for the contact hypothesis. American Psychologist, 60(7), 697-711. doi: 10.1037/0003-066X.60.7.697

Dovidio, J. F., Gaertner, S. L., \& Kawakami, K. (2003). Intergroup contact: The past, present, and the future. Group Processes \& Intergroup Relations, 6(1), 5-21. doi: $10.1177 / 1368430203006001009$

EBSCO (2014). Academic search complete. Retrieved June 29, 2014, from EBSCO http://www.ebscohost.com/documents/flyer/academic/academic-search-complete Fejes, F., \& Petrich, K. (1993). Invisibility, homophobia and heterosexism: Lesbians, gays and the media. Critical Studies in Mass Communication, 10(4). doi: $10.1080 / 15295039309366878$ 
Fredriksen-Goldsen, K., Cook-Daniels, L., Kim, H. J., Erosheva, E. A., Emlet, C. A., Hoy-Ellis, C. P., . . . Muraco, A. (2014). Physical and mental health of transgender older adults: An at-risk and underserved population. Gerontologist, 54(3), 488-500. doi: 10.1093/geront/gnt021

Fredriksen-Goldsen, K., \& Muraco, A. (2010). Aging and sexual orientation: A 25-year review of the literature. Research on Aging, 32(3), 372-413. doi:

$10.1177 / 0164027509360355$

Fredriksen-Goldsen, K. I. (2011). Resilience and disparities among lesbian, gay, bisexual, and transgender older adults. Public Policy \& Aging Report, 21(3), 3-7. doi: 10.1093/ppar/21.3.3

Fredriksen-Goldsen, K. I., \& Kim, H.-J. (2014). Count me in: Response to sexual orientation measures among older adults. Research on Aging, 37(5), 464-480. doi: $10.1177 / 0164027514542109$

Graham, H. E., Frame, M. C., \& Kenworthy, J. B. (2014). The moderating effect of prior attitudes on intergroup face-to-face contact. Journal of Applied Social Psychology, 44(8), 547-556. doi: 10.1111/jasp.12246

Greene, J. C., \& Caracelli, V. J. (2003). Making paradigmatic sense of mixed methods practice. In C. Teddlie \& A. Tashakkori (Eds.), Handbook of mixed methods in social and behavioral research (pp. 91-110). Thousand Oaks, CA: Sage.

Heinze, J. E. H. S. S. (2009). Intergroup contact and beliefs about homosexuality in adolescence. Journal of Youth \& Adolescence, 38(7), 937. doi: 10.1007/s10964009-9408-X 
Henderson, A. C., \& Murdock, J. L. (2012). Getting students beyond ideologies: Using heterosexist guided imagery in the classroom. Innovative Higher Education, 37(3), 185-198. doi: 10.1007/s10755-011-9198-4

Herek, G. M. (1988). Heterosexuals' attitudes toward lesbians and gay men: Correlates and gender differences. Journal of Sex Research, 25(4), 451-477.

Herek, G. M. (2000). Sexual prejudice and gender: Do heterosexuals' attitudes toward lesbians and gay men differ? Journal of Social Issues, 56(2), 251-266. doi: $10.1111 / 0022-4537.00164$

Herek, G. M. (2007). Confronting sexual stigma and prejudice: Theory and practice. Journal of Social Issues, 63(4), 905-925. doi: 10.1111/j.1540-4560.2007.00544.x

Herek, G. M., \& Capitanio, J. P. (1996). " Some of my best friends": Intergroup contact, concealable stigma, and heterosexuals' attitudes toward gay men and lesbians. Personality and Social Psychology Bulletin, 22, 412-424.

Herek, G. M., \& McLemore, K. A. (2013). Sexual prejudice. Annual Review of Psychology, 64(1), 309-333. doi: 10.1146/annurev-psych-113011-143826

Hinrichs, K. L. M., \& Vacha-Haase, T. (2010). Staff perceptions of same-gender sexual contacts in long-term care facilities. Journal of Homosexuality, 57(6), 776-789. doi: $10.1080 / 00918369.2010 .485877$

Hodson, G. (2011). Do ideologically intolerant people benefit from intergroup contact? Current Directions in Psychological Science, 20(3), 154-159. doi:

$10.1177 / 0963721411409025$ 
Hoaglin, D. C., Iglewicz, B., \& Tukey, J. W. (1986). Performance of some resistant rules for outlier labeling. Journal of the American Statistical Association, 81(396), 991999.

Horowitz, E. L. (1936). The development of attitude toward the negro. Archives of Psychology (Columbia University), 194, 47.

Human Rights Campaign ([HRC] 2014a). Hospital visitation laws (pp. 1). Washington, DC: Human Rights Campaign.

HRC. (2014b). Public accomodations laws \& policies (pp. 1). Washington, DC: Human Rights Campaign.

HRC. (2014c). Statewide housing laws \& policies (pp. 1). Washington, DC: Human Rights Campaign.

Hudson, R. (2011). Integrating lesbian, gay, bisexual, and transgender older adults into aging policy and practice. Public Policy \& Aging Report, 21(3), 2. doi: 10.1093/ppar/21.3.2

Hughes, A. K., Harold, R. D., \& Boyer, J. M. (2011). Awareness of lgbt aging issues among aging services network providers. Journal of Gerontological Social Work, 54(7), 659-677. doi: 10.1080/01634372.2011.585392

IOM. (2011). The health of lesbian, gay, bisexual, and transgender people building a foundation for better understanding. Institute of Medicine. Retrieved from http://www.nap.edu/openbook.php?record_id=13128

Knochel, K., Croghan, C. F., Moone, R. P., \& Quam, J. K. (2012). Training, geography, and provision of aging services to lesbian, gay, bisexual, and transgender older 
adults. Journal of Gerontological Social Work, 55(5), 426-443. doi:

$10.1080 / 01634372.2012 .665158$

Knochel, K., Quam, J. K., \& Croghan, C. F. (2011). Are old lesbian and gay people well served?: Understanding the perceptions, preparation, and experiences of aging services providers. Journal of Applied Gerontology, 30(3), 370-389. doi:

$10.1177 / 0733464810369809$

LaMar, L., \& Kite, M. (1998). Sex differences in attitudes toward gay men and lesbians: A multidimensional perspective. Journal of Sex Research, 35(2), 189-196. doi: $10.1080 / 00224499809551932$

Leyva, V. L., Breshears, E. M., \& Ringstad, R. (2013). Assessing the efficacy of lgbt cultural competency training for aging services providers in California's central valley. Journal of Gerontological Social Work, 57(2-4), 335-348. doi: $10.1080 / 01634372.2013 .872215$

Maddux, S. (Writer). (2010). Gen silent. In S. Maddux (Producer). United States: MadStu Productions.

McDermott, D. T., \& Blair, K. L. (2012). 'What's it like on your side of the pond?': A cross-cultural comparison of modern and old-fashioned homonegativity between North American and European samples. Psychology \& Sexuality, 3(3), 277-296. doi: $10.1080 / 19419899.2012 .700032$

MetLife. (2010). Still out, still aging: The metlife study of lesbian, gay, bisexual and transgender baby boomers. MetLife Mature Market Institute: Westport, CT. 
Meyer, I. H. (2003). Prejudice, social stress, and mental health in lesbian, gay, and bisexual populations: Conceptual issues and research evidence. Psychological Bulletin, 129(5), 674. doi: 10.1037/0033-2909.129.5.674

Meyer, I. H., Dietrich, J., \& Schwartz, S. (2008). Lifetime prevalence of mental disorders and suicide attempts in diverse lesbian, gay, and bisexual populations. American Journal of Public Health, 98(6), 1004-1006. doi: 10.2105/AJPH.2006.096826

Mohaupt, J., van Soeren, M., Andrusyszyn, M., MacMillan, K., Devlin-Cop, S., \& Reeves, S. (2012). Understanding interprofessional relationships by the use of contact theory. Journal of Interprofessional Care, 26(5), 370-375. doi: $10.3109 / 13561820.2012 .673512$

Morales, M. J., King, M. D., Hiler, H., Coopwood, M. S., \& Wayland, S. (2014). The greater St. Louis lgbt health and human services needs assessment: An examination of the silent and baby boom generations. Journal of Homosexuality, 61(1), 103-128. doi: 10.1080/00918369.2013.835239

Morgan, D. L. (2014). Integrating qualitative and quantitative methods : A pragmatic approach. Thousand Oaks, CA: Sage.

NASW. (2008). Code of ethics of the national association of social workers. Washington, DC: NASW Press.

Orel, N. (2006). Documenting the need for affirmative services for lgb older adults. In D. C. Kimmel, T. Rose \& S. David (Eds.), Lesbian, gay, bisexual, and transgender aging: Research and clinical perspectives (pp. 227-246). New York, NY: Columbia University Press. 
Ortman, J., Velkoff, V., \& Hogan, H. (2014). An aging nation: The older population in the United States. United States Census Bureau, 1-28. Retrieved from http://www.census.gov/library/publications/2014/demo/p25-1140.html

Oswalt, S. B., \& Wyatt, T. J. (2011). Sexual orientation and differences in mental health, stress, and academic performance in a national sample of U.S. college students. Journal of homosexuality, 58(9), 1255-1280. doi: 10.1080/00918369.2011.605738

Paluck, E. L. (2006). Diversity training and intergroup contact: A call to action research. Journal of Social Issues, 62(3), 577-595. doi: 10.1111/j.1540-4560.2006.00474.x

Payne, D., Jebb, P., Brathwaite, B., \& Crumbie, A. (2014). Readers panel. Essential lessons in respect. Nursing Standard, 28(23), 28-29.

Pelts, M. D. (2014). A look back at the defense of marriage act: Why same-sex marriage is still relevant for social work. Affilia, 29(2), 237-247. doi:

$10.1177 / 0886109913519793$

Perrin, N., \& Powowy, J. (Eds.). (2008). The role of the social worker in the long-term care facility. Jefferson City, MO: Missouri Long-Term Care Ombudsman Program.

Pettigrew, T. F. (1998). Intergroup contact theory. Annual Review of Psychology, 49, 6585. doi: 10.1146/annurev.psych.49.1.65

Pettigrew, T. F., \& Tropp, L. (2006). A meta-analytic test of intergroup contact theory. Journal of personality and social psychology, 90(5), 751. doi: 10.1037/00223514.90 .5 .751 
Pettigrew, T. F., \& Tropp, L. (2011). When groups meet: The dynamics of intergroup contact. New York, NY, Psychology Press.

Pettigrew, T. F., Tropp, L., Wagner, U., \& Christ, O. (2011). Recent advances in intergroup contact theory. International Journal of Intercultural Relations, 35(3), 271-280.

Pickett, B. L. (2009). Historical dictionary of homosexuality (Vol. 96). Plymouth, UK: Scarecrow Press.

Porter, K. E., \& Krinsky, L. (2014). Do lgbt aging trainings effectuate positive change in mainstream elder service providers? Journal of homosexuality, 61(1), 197-216.

Portz, J. D., Retrum, J. H., Wright, L. A., Boggs, J. M., Wilkins, S., Grimm, C., . . . Gozansky, W. S. (2014). Assessing capacity for providing culturally competent services to lgbt older adults. Journal of Gerontological Social Work, 57(2-4), 305321. doi: $10.1080 / 01634372.2013 .857378$

Richards, L., \& Morse, J. M. (2013). Readme first for a user's guide to qualitative methods (3rd ed.). Thousand Oaks, CA: Sage.

Ritzer, G. (Ed.). (2007). The blackwell encyclopedia of sociology; $11 v$ (Vol. 22). Portland, OR: Ringgold Inc.

Rodenborg, N., \& Huynh, N. (2006). On overcoming segregation: Social work and intergroup dialogue. Social Work with Groups, 29(1), 27-44. doi: 10.1300/J009v29n01_04

Rogers, A., Rebbe, R., Gardella, C., Worlein, M., \& Chamberlin, M. (2013). Older lgbt adult training panels: An opportunity to educate about issues faced by the older 
lgbt community. Journal of Gerontological Social Work, 56(7), 580-595. doi:

$10.1080 / 01634372.2013 .811710$

Rosik, C. H. (2007). Ideological concerns in the operationalization of homophobia, part I: An analysis of Herek's ATLG-R scale. Journal of Psychology and Theology, $35(2), 132-144$.

Rudestam, K. E., \& Newton, R. R. (1992). Surviving your dissertation : A comprehensive guide to content and process. Newbury Park, CA.: SAGE.

Saguy, T., Tausch, N., Dovidio, J. F., \& Pratto, F. (2009). The irony of harmony intergroup contact can produce false expectations for equality. Psychological Science, 20(1), 114-121.

Saldaña, J. (2013). The coding manual for qualitative researchers ( $2 \mathrm{nd}$ ed.). Thousand Oaks, CA: Sage.

Schirm, V., Albanese, T., Garland, T. N., Gipson, G., \& Blackmon, D. J. (2000). Caregiving in nursing homes: Views of licensed nurses and nursing assistants. Clinical Nursing Research, 9(3), 280-297. doi: 10.1177/10547730022158591

Sherman, M. D., Kauth, M. R., Shipherd, J. C., \& Street, R. L. (2014). Provider beliefs and practices about assessing sexual orientation in two veterans health affairs hospitals. LGBT Health. doi: 10.1089/lgbt.2014.0008

Shilts, R. (1994). Conduct unbecoming: Lesbians and gays in the us military, Vietnam to the Persian Gulf. New York, NY: St Martin's Press.

Singer, H. A. (1948). The veteran and race relations. Journal of Educational Sociology, 21(7), 397-408. doi: 10.2307/2263899 
Smith, F. T. (1943). An experiment in modifying attitudes toward the negro. Teachers College Contributions to Education. 887, xii +135.

Smith, S. J., Axelton, A. M., \& Saucier, D. A. (2009). The effects of contact on sexual prejudice: A meta-analysis. Sex Roles, 61(3-4), 178-191. doi: 10.1007/s11199009-9627-3

Stephan, W. G., \& Stephan, C. W. (2001). Improving intergroup relations. Thousand Oaks, CA: Sage Publications.

Teddlie, C., \& Tashakkori, A. (2009). Foundations of mixed methods research: Integrating quantitative and qualitative approaches in the social and behavioral sciences. Thousand Oaks, CA: Sage Publications

U.S Census Bureau (n.d.). Factfinder search. Accessed http://factfinder.census.gov/faces/nav/jsf/pages/index.xhtml

Valdiserri, R. O. (2011). Thirty years of AIDS in america: A story of infinite hope. AIDS Education \& Prevention, 23(6), 479-494. doi: 10.1521/aeap.2011.23.6.479

Wilkinson, W. W. (2006). Exploring heterosexual women's anti-lesbian attitudes. Journal of Homosexuality, 51(2), 139-155. doi: 10.1300/J082v51n02_08

Wilkinson, W. W. (2008). Threatening the patriarchy: Testing an explanatory paradigm of anti-lesbian aatitudes. Sex Roles, 59(7-8), 512-520. doi: 10.1007/s11199-008$9432-4$

Williams, C. C. (2007). Mixed-method evaluation of continuing professional development: Applications in cultural competence training. Social Work Education, 26(2), 121-135. doi: 10.1080/02615470601042623 
Yin, R. K. (2010). Qualitative research from start to finish. New York, NY: Guilford Press.

Zeligs, R., \& Hendrickson, G. (1933). Racial attitudes of 200 sixth grade children.

Sociology \& Social Research, 18, 26-36. 


\section{Appendix A}

Recruitment Flyer

\section{Are you an Employee in a Long-term Care Facility?}

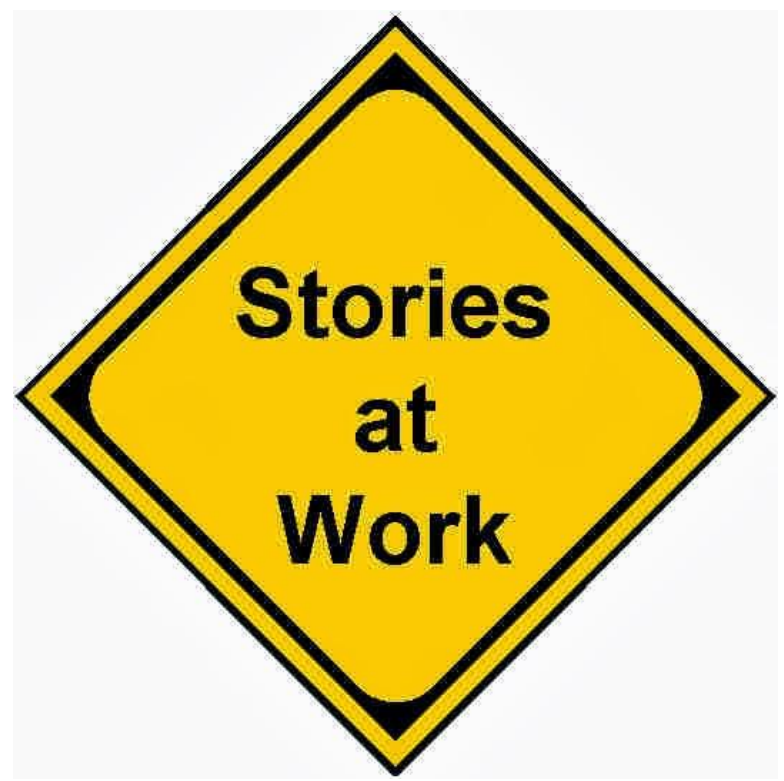

An individual who identifies as lesbian or gay will discuss how their life history influences their views on life and aging

This event is part of a dissertation research project and is being conducted by a doctoral student at the University of Missouri, School of Social work.

Your input will aid in the design of future training.

Participation is voluntary! The entire event is expected to last one hour and will include a 10 minute pre-survey, 20 minute storytelling event, 20 minute group discussion and 10 minute post survey.

All information collected during the event will be maintained in a manner to protect your privacy.

Participants will receive a $\$ 20$ gift card for their time and effort.

Questions or for more information:

$$
\text { Michael Pelts, MSW }
$$




\section{Appendix B}

Survey A

(Survey A, page 1 of 2)

Facility:

Date:

1. What is your age?

2. What is your gender?

3. What is your level of education?

High school

Certificate program

Associate's degree

Bachelor's degree

Master's degree

Doctoral degree (PhD, MD)

Other (please specify)

4. What is your current Relationship status?

Single

Married

Partnered - living together

Partnered - not living together

Divorced

Widowed

Other (please specify)

5. What is your race/ethnicity?

6. How often do you attend religious services?

One time each week or more?

At least one time a month?

A few times each year?

One time per year?

Do not attend religious services

7. How religious are you?

Not at all

Not Very

Somewhat

Very
8. What is your religion?

9. How do you describe yourself politically?

Democrat

Republican

Independent

Other (please specify)

10. Do you personally have any friends who are:

lesbian women?

gay men?

Comments:

11. Do you have any family members who are:

$\begin{array}{lll} & \text { Yes } & \text { No } \\ \text { lesbian women? } & \square & \square \\ \text { gay men? } & \square & \square \\ \text { Comments: } & & \end{array}$

12. What is your current job title?

13. How many years have you worked in longterm care settings?

14. How long have you worked at this facility?

15. Does your employer have a policy that prohibits discrimination based on sexual orientation?

$\square$ Yes

No

Don't know

16. What is your sexual orientation? 
(Survey A, page 2 of 2)

\begin{tabular}{|c|c|c|c|c|c|}
\hline & $\begin{array}{c}\text { Strongly } \\
\text { Disagree } \\
1\end{array}$ & 2 & Agree & 4 & $\begin{array}{c}\text { Strongly } \\
\text { Agree } \\
5\end{array}$ \\
\hline $\begin{array}{l}\text { The increasing acceptance of lesbians in our } \\
\text { society is aiding in the deterioration of morals }\end{array}$ & 1 & 2 & 3 & 4 & 5 \\
\hline Lesbians endanger the institution of the family & 1 & 2 & 3 & 4 & 5 \\
\hline $\begin{array}{l}\text { Many lesbians are very moral and ethical } \\
\text { people }\end{array}$ & 1 & 2 & 3 & 4 & 5 \\
\hline $\begin{array}{l}\text { Lesbian couples should be able to adopt } \\
\text { children the same as heterosexual couples }\end{array}$ & 1 & 2 & 3 & 4 & 5 \\
\hline $\begin{array}{l}\text { The idea of marriages between lesbians seems } \\
\text { ridiculous to me }\end{array}$ & 1 & 2 & 3 & 4 & 5 \\
\hline $\begin{array}{l}\text { State laws regulating private, consenting } \\
\text { behavior between lesbians should be loosened }\end{array}$ & 1 & 2 & 3 & 4 & 5 \\
\hline Lesbians just can't fit into our society & 1 & 2 & 3 & 4 & 5 \\
\hline Lesbians do need psychological treatment & 1 & 2 & 3 & 4 & 5 \\
\hline Lesbians are a viable part of our society & 1 & 2 & 3 & 4 & 5 \\
\hline $\begin{array}{l}\text { Homosexual behavior between two women is } \\
\text { just plain wrong }\end{array}$ & 1 & 2 & 3 & 4 & 5 \\
\hline $\begin{array}{l}\text { The increasing acceptance of gay men in our } \\
\text { society is aiding in the deterioration of morals }\end{array}$ & 1 & 2 & 3 & 4 & 5 \\
\hline Gay men endanger the institution of the family & 1 & 2 & 3 & 4 & 5 \\
\hline $\begin{array}{l}\text { Many gay men are very moral and ethical } \\
\text { people }\end{array}$ & 1 & 2 & 3 & 4 & 5 \\
\hline $\begin{array}{l}\text { Gay male couples should be able to adopt } \\
\text { children the same as heterosexual couples }\end{array}$ & 1 & 2 & 3 & 4 & 5 \\
\hline $\begin{array}{l}\text { The idea of marriages between gay men seems } \\
\text { ridiculous to me }\end{array}$ & 1 & 2 & 3 & 4 & 5 \\
\hline
\end{tabular}




\begin{tabular}{|c|c|c|c|c|c|}
\hline & \begin{tabular}{|c} 
Strongly \\
Disagree \\
1
\end{tabular} & 2 & Agree & 4 & $\begin{array}{c}\text { Strongly } \\
\text { Agree } \\
5\end{array}$ \\
\hline $\begin{array}{l}\text { State laws regulating private, consenting } \\
\text { behavior between gay men should be loosened }\end{array}$ & 1 & 2 & 3 & 4 & 5 \\
\hline Gay men just can't fit into our society & 1 & 2 & 3 & 4 & 5 \\
\hline Gay men do need psychological treatment & 1 & 2 & 3 & 4 & 5 \\
\hline Gay men are a viable part of our society & 1 & 2 & 3 & 4 & 5 \\
\hline $\begin{array}{l}\text { Homosexual behavior between two men is just } \\
\text { plain wrong }\end{array}$ & 1 & 2 & 3 & 4 & 5 \\
\hline $\begin{array}{l}\text { Long-term care providers should acknowledge } \\
\text { same-sex partners equally to any other next of } \\
\text { kin }\end{array}$ & 1 & 2 & 3 & 4 & 5 \\
\hline $\begin{array}{l}\text { Lesbian and gay older adults deserve the same } \\
\text { quality of care as heterosexual older adults }\end{array}$ & 1 & 2 & 3 & 4 & 5 \\
\hline $\begin{array}{l}\text { I am comfortable providing care to lesbian or } \\
\text { gay older adults }\end{array}$ & 1 & 2 & 3 & 4 & 5 \\
\hline
\end{tabular}




\section{Appendix C}

Survey B

(Survey B, page 1 of 2)

\begin{tabular}{|c|c|c|c|c|c|}
\hline & $\begin{array}{c}\text { Strongly } \\
\text { Disagree } \\
1\end{array}$ & 2 & Agree & 4 & $\begin{array}{c}\text { Strongly } \\
\text { Agree } \\
5\end{array}$ \\
\hline $\begin{array}{l}\text { The increasing acceptance of lesbians in our } \\
\text { society is aiding in the deterioration of morals }\end{array}$ & 1 & 2 & 3 & 4 & 5 \\
\hline Lesbians endanger the institution of the family & 1 & 2 & 3 & 4 & 5 \\
\hline $\begin{array}{l}\text { Many lesbians are very moral and ethical } \\
\text { people }\end{array}$ & 1 & 2 & 3 & 4 & 5 \\
\hline $\begin{array}{l}\text { Lesbian couples should be able to adopt } \\
\text { children the same as heterosexual couples }\end{array}$ & 1 & 2 & 3 & 4 & 5 \\
\hline $\begin{array}{l}\text { The idea of marriages between lesbians seems } \\
\text { ridiculous to me }\end{array}$ & 1 & 2 & 3 & 4 & 5 \\
\hline $\begin{array}{l}\text { State laws regulating private, consenting } \\
\text { behavior between lesbians should be loosened }\end{array}$ & 1 & 2 & 3 & 4 & 5 \\
\hline Lesbians just can't fit into our society & 1 & 2 & 3 & 4 & 5 \\
\hline Lesbians do need psychological treatment & 1 & 2 & 3 & 4 & 5 \\
\hline Lesbians are a viable part of our society & 1 & 2 & 3 & 4 & 5 \\
\hline $\begin{array}{l}\text { Homosexual behavior between two women is } \\
\text { just plain wrong }\end{array}$ & 1 & 2 & 3 & 4 & 5 \\
\hline $\begin{array}{l}\text { The increasing acceptance of gay men in our } \\
\text { society is aiding in the deterioration of morals }\end{array}$ & 1 & 2 & 3 & 4 & 5 \\
\hline Gay men endanger the institution of the family & 1 & 2 & 3 & 4 & 5 \\
\hline $\begin{array}{l}\text { Many gay men are very moral and ethical } \\
\text { people }\end{array}$ & 1 & 2 & 3 & 4 & 5 \\
\hline $\begin{array}{l}\text { Gay male couples should be able to adopt } \\
\text { children the same as heterosexual couples }\end{array}$ & 1 & 2 & 3 & 4 & 5 \\
\hline
\end{tabular}




\begin{tabular}{|c|c|c|c|c|c|}
\hline & $\begin{array}{c}\text { Strongly } \\
\text { Disagree } \\
1\end{array}$ & 2 & Agree & 4 & $\begin{array}{c}\text { Strongly } \\
\text { Agree } \\
5\end{array}$ \\
\hline $\begin{array}{l}\text { The idea of marriages between gay men seems } \\
\text { ridiculous to me }\end{array}$ & 1 & 2 & 3 & 4 & 5 \\
\hline $\begin{array}{l}\text { State laws regulating private, consenting } \\
\text { behavior between gay men should be loosened }\end{array}$ & 1 & 2 & 3 & 4 & 5 \\
\hline Gay men just can't fit into our society & 1 & 2 & 3 & 4 & 5 \\
\hline Gay men do need psychological treatment & 1 & 2 & 3 & 4 & 5 \\
\hline Gay men are a viable part of our society & 1 & 2 & 3 & 4 & 5 \\
\hline $\begin{array}{l}\text { Homosexual behavior between two men is just } \\
\text { plain wrong }\end{array}$ & 1 & 2 & 3 & 4 & 5 \\
\hline $\begin{array}{l}\text { Long-term care providers should acknowledge } \\
\text { same-sex partners equally to any other next of } \\
\text { kin }\end{array}$ & 1 & 2 & 3 & 4 & 5 \\
\hline $\begin{array}{l}\text { Lesbian and gay older adults deserve the same } \\
\text { quality of care as heterosexual older adults }\end{array}$ & 1 & 2 & 3 & 4 & 5 \\
\hline $\begin{array}{l}\text { I am comfortable providing care to lesbian or } \\
\text { gay older adults }\end{array}$ & 1 & 2 & 3 & 4 & 5 \\
\hline
\end{tabular}

1. What did you find surprising about this story?

2. Are there things you heard in the story that will change the way you do your job? If yes, what?

3. How did this training change the way you view lesbian and gay older adults? 
4. What type of information would you like to receive training about working with lesbian and gay older adults?

5. Other comments:

Thank you! 


\section{Appendix D}

\section{Role of Note-taker and Observer}

To assist with the process, a research assistant will be utilized to assist with taking notes and making observations. A student from the University of Missouri will be sought who possesses good listening skills, recording skills and observational skills associated with collecting qualitative data. Tasks with include:

1. Assist in arranging the room in a manner that facilitates discussion

2. Managing the recording process and ensuring the session is being recorded
a. Having the recorder available
b. Checking for backup batteries
c. Checking for backup recording device
d. Testing the recorder prior to the start of each session

3. Assisting with consenting process

a. Distributing consent forms to participants

b. Assisting with answering individual questions about consent form

c. Collecting consent forms

4. Assisting with pre-storytelling survey

a. Distributing random numbers to participants

b. Distributing Survey A to participants

c. Assisting participants with answering individual questions about the survey

d. Ensuring each participant records their randomly assigned research number on Survey A

e. Collecting Survey A forms

5. Taking notes related to setting and comments made during the discussion as outlined in the Recording Form (Appendix E).

6. Assisting with post-storytelling survey

a. Distributing survey B to participants

b. Assisting participants with answering individual questions about the survey

c. Ensuring each participant records their randomly assigned research number on Survey B

d. Collecting survey B forms

7. Assisting with gift card process

a. Collecting cards that contain randomly assigned research numbers

b. Drawing card for selection of gift card recipient

8. Debrief with primary researcher and storyteller following the group discussion

9. Review and discuss primary researcher's interpretation of qualitative data 


\section{Appendix E}

\section{Consent to Participate in Research Study \\ University of Missouri-Columbia Social Work Program}

(Consent, page 1 of 2 )

\author{
A Study of Inter-Group Contact Theory: Using \\ Storytelling to Increase Awareness of Lesbian and Gay \\ Older Adults in Long-term Care Settings \\ Principal Investigator: Michael Pelts, MSW \\ Contact Information: \\ $7^{\text {th }}$ Floor Clark Hall, School of Social Work \\ University of Missouri \\ Columbia, MO 65211-4470 \\ Email: mdpp74@mail.missouri.edu \\ Phone: (321) 626-3458
}

\author{
Faculty Advisory: Dr. Colleen Galambos, MSW, PhD \\ Contact Information: \\ 523 Clark Hall, School of Social Work \\ University of Missouri Columbia, MO \\ $65211-4470$ \\ Email: galambosc@missouri.edu \\ Phone: (573) 882-3701
}

\section{Introduction}

You have been asked to participate in a research study that is part of the requirement for the degree of a PhD in Social Work. Before you agree to participate in this study, it is important you read about and understand the study and the procedures. If you have questions about this study, or your role in the study, please feel free to ask at the time of the study or contact Michael Pelts or Dr. Galambos (contact information above). You will need to sign this form giving us permission for you to be involved in this study. Taking part in this study is your choice. There will be no negative consequences if you do not choose to participate.

\section{Purpose of this Study}

The reason this study is being conducted is to assess the influence of storytelling on long-term care staff members' attitudes towards sexual minorities.

\section{Description of Procedures}

If you decide to take part in this study, you will be asked to fill out a pre-survey which will ask some personal information and you will be asked to answer questions about your perceptions of sexual minorities prior to the storytelling event. This questionnaire will take about 10 minutes to complete. You will then be asked to participate in a storytelling event where an individual will share how her or his life experiences impacts their perceptions of long-term care that will last for approximately 20 minutes. Following the storytelling event, participants will be asked to take part in a group discussion about the information presented that will last for 15 minutes. At the conclusion of the discussion, participants will be asked to again complete a survey about perceptions sexual minorities that will take about 10 minutes to complete. No personal information is collected on this survey. To protect your privacy, you will not be asked to disclose any identifiable information - please do not put your name on the survey. Each participant will be assigned a number that will be used to identify pre surveys with post surveys for analysis. Please write this number in the upper right hand corner of both the pre and post survey.

\section{What are the risks?}

We estimate that the potential risks of this study are minimal. However, you may experience some discomfort when answering some of the questions about your perceptions.

\section{What are the benefits?}

It is not anticipated that you will experience any direct benefits from this study. You may learn more about sexual minorities which may increase your knowledge in this area. Your input is valuable and your participation in this research will help investigators develop future training programs. Refusal to participate will involve no penalty or loss of benefits to which the subject is otherwise entitled.

\section{How will my privacy be protected?}

Surveys will be coded by number at each site to measure changes in responses before and after the storytelling event. Your name or other personal identifying information is not collected on the surveys or other points in during the process. Surveys and the recorded group conversations will be accessible only by the investigators and will be kept in a locked facility. You will not be identified by name in any publications that result from this research. All information from this study will be destroyed 7 years after the study ends.

Although the PI will make every effort, we cannot guarantee complete confidentiality of things said in the group discussion, as the actions of other focus group members cannot be controlled. All participants are encouraged to respect the group and keep the things that are said during the group discussion confidential. 
For questions about the subjects' rights, concerns, complaints or comments as a research participant please contact:

The University of Missouri, Campus Institutional Review Board, 483 McReynolds Hall, Columbia, MO 65211573.882 .9585 Website: http://www.research.missouri.edu/cirb/index.htm

\section{Will I be compensated for my participation in the study?}

You will receive a gift card to a local retailer in the amount of $\$ 20$ for your participation in this study.

\section{Consent to Participate}

I have read and understand the information on this form. I have been encouraged to ask questions and all my questions have been answered to my satisfaction. I have also been informed this is a voluntary study and I do not have to complete this study. I can withdraw at any time without any loss of benefits. By signing this form, I voluntarily agree to participate in this study. 


\section{Appendix F}

Group Discussion Guide

(Group discussion guide, page 1 of 2)

Thank you to our storyteller for sharing personal experiences from her or his life. We now have the opportunity to ask questions and talk about things we heard in the story.

\section{Introduction}

- This time is designed to be an informal discussion and question and answer period.

- Information collected here is kept confidential and your name is not associated with your comments - your participation is voluntary.

- Your input is important - there are no right or wrong questions, comments or opinions. Differing opinions are welcomed.

- Please speak one at a time to help facilitate a smooth discussion.

- We will keep this discussion to 15 or 20 minutes to respect everybody's time. At the end there will be a survey and the drawing for the gift card.

\section{Questions for Facilitating Group Discussion}

1. To start, are there any questions or comments for our storyteller?

2. How did the story influence your perceptions about lesbians and gay older adults?

3. What are your thoughts about the information you heard in the story and how lived experiences influence perceptions of residents entering long-term care?

4. Have you considered there may be gay or lesbian residents in this facility or facilities where you have worked?

5. Is there anything else that people would like to share or ask as we begin to bring this discussion to an end?

\section{Seeking Clarification and More Information}

Efforts will be made to avoid leading questions when soliciting a deeper understanding. General probes such as, "please explain what you mean by..." and "please talk more about ..." will be used to clarify and elicit further information.

\section{Addressing Dominate Participants or Dominate Topic Areas}

If the discussion centers on only one broad area or one individual is dominating the discussion, a question such as "Does anybody have a different view they would like to share?" or "what are others thoughts?" will be used to solicit varied input. 


\section{Conclusion}

Thank you to all of you for participating in this event and providing your valuable feedback. This information is very helpful for understanding and designing future training related to this topic and other topics.

Please take a few minutes now to complete the final questionnaire. There are no background questions on this form. Please be sure to write your research number in the upper right hand corner and also turn in your number card to receive the $\$ 20$ gift card. 


\section{Appendix G}

Guide for Developing Storytelling Script

Information in this guide is informed by the theory of intergroup contact and by the overarching goal of this research project. The following elements serve as an example of broad areas that will be used to develop the individual story that will be used as the intervention. An outline of the actual story that is developed will appear included in the final version of the dissertation.

1. Introduction - Key dates and events of the person's life such as place of birth, significant events of family upbringing, career, etc.

2. Coming out process - Disclosing status as a lesbian or gay man to significant people in life.

- Positive consequences

○ Affirmation

- Negative consequences

○ Rejection

○ Societal stigma

- Coping with stigma of identifying as sexual minority

○ Hiding sexual orientation

- Relationships

- Challenges of interacting with social institutions

3. Recollections of major events related to sexual minorities

- Anthologizing of "homosexuality"

○ Criminal

- Mental illness

- Civil rights advances

- Stonewall riots

- Election of Harvey Milk

○ Assassination of Harvey Milk

- HIV/AIDS epidemic

- Significance of Domestic Partnerships and Marriage

4. How identification as a sexual minority influences healthcare experiences

- Negative experiences

- Positive experiences

- Informs perceptions of long-term care

$\circ$ Others stories of long-term care

- Fears 


\section{VITA}

Michael Dwayne Pelts was born in Cedar Rapids, Iowa. Michael graduated from the University of Southern Mississippi with a Bachelor's Degree in Social and Rehabilitation Services in 1991. He worked for several years in direct service and administering social services programs in Tennessee and Florida before pursuing the Masters of Social Work (MSW) Degree. Michael graduated from Portland State University with the MSW Degree in 2010. Following graduation, Michael worked as a psychiatric social worker in forensic mental health for the State of Washington for two years. He entered the doctoral program at the University of Missouri in August 2012. From August 2012 to August 2015 Michael worked as a graduate assistant performing research and teaching activities in a variety settings. Research included activities related to school social work, military members and veterans, and gerontechnology. Work as a graduate research assistant on a large, empirical, interdisciplinary study funded by the National Institutes of Health, inspired work for Michael's dissertation. In August 2015, Michael accepted a visiting instructor position at the University of Southern Mississippi while completing his dissertation. Michael successfully defended his dissertation on November 5, 2015 and graduated from the University of Missouri in December of 2015. He plans to continue teaching and developing his research. 